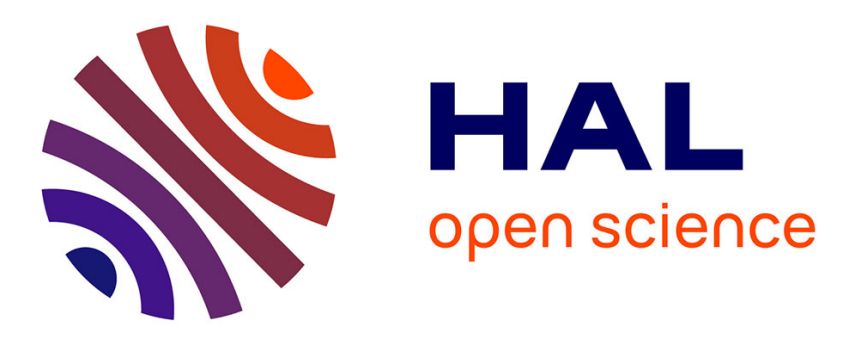

\title{
Controlled preparation and characterization of Pt-Rh/Al2O3 bimetallic catalysts for reactions in reducing conditions
}

Nelly Herault, Lilian Olivet, Laurence Pirault-Roy, Catherine Especel, Maria A. Vicerich, Carlos L. Pieck, Florence Epron

\section{To cite this version:}

Nelly Herault, Lilian Olivet, Laurence Pirault-Roy, Catherine Especel, Maria A. Vicerich, et al.. Controlled preparation and characterization of $\mathrm{Pt}-\mathrm{Rh} / \mathrm{Al} 2 \mathrm{O} 3$ bimetallic catalysts for reactions in reducing conditions. Applied Catalysis A : General, 2016, 517, pp.81-90. 10.1016/j.apcata.2016.02.024 . hal01342597

\section{HAL Id: hal-01342597 \\ https://hal.science/hal-01342597}

Submitted on 31 Aug 2021

HAL is a multi-disciplinary open access archive for the deposit and dissemination of scientific research documents, whether they are published or not. The documents may come from teaching and research institutions in France or abroad, or from public or private research centers.
L'archive ouverte pluridisciplinaire HAL, est destinée au dépôt et à la diffusion de documents scientifiques de niveau recherche, publiés ou non, émanant des établissements d'enseignement et de recherche français ou étrangers, des laboratoires publics ou privés. 


\section{Controlled preparation and characterization of $\mathrm{Pt}-\mathrm{Rh} / \mathrm{Al}_{2} \mathrm{O}_{3}$ \\ bimetallic catalysts for reactions in reducing conditions}

Nelly Hérault ${ }^{\mathrm{a}}$, Lilian Olivet ${ }^{\mathrm{a}}$, Laurence Pirault-Roy ${ }^{\mathrm{a}}$, Catherine Especel $^{\mathrm{a}}$, María A. Vicerich ${ }^{\mathrm{b}}$, Carlos L. Pieck ${ }^{\mathrm{b}}$ and Florence Epron ${ }^{\mathrm{a} *}$

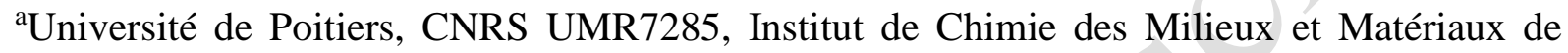
Poitiers, B27, TSA 51106, 4 rue Michel Brunet, 86073 Poitiers CEDEX 9, France.

${ }^{\mathrm{b}}$ Instituto de Investigaciones en Catálisis y Petroquímica (INCAPE) (FIQ-UNL, CONICET), Colectora Ruta Nac. N 168 Km. 0 - Paraje El Pozo, CP 3000 Santa Fe, Argentina.

Phone : + 33549454832

email : florence.epron@univ-poitiers.fr 


\begin{abstract}
:
Pt-Rh bimetallic catalysts on alumina support were prepared according to three different techniques, one leading to random deposition of the two metals at the support's surface, the two others, namely the organometallic grafting and the colloidal route, favoring the formation of bimetallic particles with strong Pt-Rh interactions. Catalysts were characterized by ICP, $\mathrm{H}_{2}$ chemisorption, TPR, FTIR of chemisorbed CO and NO-CO. Then they were evaluated in cyclohexane dehydrogenation and methylcyclopentane hydrogenolysis reactions. Strong interaction between $\mathrm{Pt}$ and $\mathrm{Rh}$ was demonstrated for catalysts prepared by controlled preparation method, which leads to a strong synergetic effect for methylcyclopentane ringopening, in terms of activity and selectivity, whereas these interactions do not play a role in cyclohexane dehydrogenation.
\end{abstract}

Key-words: Bimetallic supported catalysts, Pt-Rh, cyclohexane dehydrogenation, FTIR of $\mathrm{CO}$, FTIR of NO-CO. 


\section{Introduction}

Pt-Rh bimetallic systems were demonstrated in the late 1980's as efficient bimetallic three-way catalysts for reducing $\mathrm{NO}$ and oxidizing $\mathrm{CO}$. While both metals are active for these two reactions, a synergetic effect between the two metals was proposed to explain the remarkable stability and higher activity of the aged bimetallic catalysts supported on alumina compared to the monometallic ones [1]. Recently, Pt-Rh bimetallic catalysts were presented as active and selective systems for the ring-opening of cyclic hydrocarbons [2-4], whereas rhodium and platinum supported monometallic catalysts present a poor selectivity to ring-opening products (ROP). This specific behavior of the bimetallic Pt-Rh catalysts was demonstrated as depending on the preparation method, and was attributed to the presence of bimetallic Pt-Rh alloys, i.e. $\mathrm{Pt}-\mathrm{Rh}$ entities in strong interaction, at the metal particle surface, as identified by $\mathrm{CO}$ chemisorption followed by Fourier Transformed Infra-red (FTIR) spectroscopy. However, it was not possible to quantify, by this technique, the amount of $\mathrm{Pt}, \mathrm{Rh}$ and $\mathrm{Pt}-\mathrm{Rh}$ alloy at the catalyst surface.

The objective of the present study was to prepare bimetallic Pt-Rh catalysts supported on $\gamma$ alumina with various types or degrees of interaction between rhodium and platinum and to characterize them by various techniques, and more particularly by FTIR of NO and CO, which was demonstrated as an efficient way to quantify the amount of accessible $\mathrm{Pt}, \mathrm{Rh}$, and $\mathrm{Pt}-\mathrm{Rh}$ alloys at the metallic particle surface [5], in order to rationalize the effect of the preparation method on both the Pt-Rh interactions and the particle surface composition. For this purpose, we chose three different techniques known for favoring or not the formation of bimetallic entities and tried to control the metal particle size $(<4 \mathrm{~nm}$ expected): 
- Classical coimpregnation, used as a reference. By this procedure, a random deposition of both metals ( Rh and Pt) may occur on the support.

- Surface modification of a parent monometallic catalyst by addition of the second metal by organometallic grafting. According to this procedure, core-shell particles should be obtained. The result strongly depends on the monometallic catalyst particle size, which may vary in the reaction medium.

- Formation of bimetallic particles in solution, by a colloidal way, using a polymer for stabilizing metallic particles. This type of synthesis leads to homogeneous particle sizes with generally strong metallic interactions. The two key-points of this technique are the deposition on the support and the removal of the polymer or the surfactant.

The effect of the interactions between platinum and rhodium will be evaluated on two test reactions, cyclohexane dehydrogenation and methylcyclopentane ring-opening. Cyclohexane dehydrogenation is a simple reaction for which the activity of a monometallic catalyst will mainly depend on the nature of the metal and on its accessibility, whereas for bimetallic catalyst, it will be a function of the amount of each metal at the surface if their activity is very different. This reaction could be then an effective means to estimate the amount of rhodium and platinum at the surface of bimetallic particles. As far as methylcyclopentane ring-opening reaction is concerned, strong interactions between these two metals, with the formation of alloyed entities, will lead to synergetic effects and then to higher performances than those of the monometallic catalysts [2-3]. Consequently, this reaction is used in the present study to verify the formation of alloyed species depending on the preparation method. 


\section{Experimental}

\subsection{Catalysts preparation}

An alumina (AluminumOxidC (Degussa)) with a specific surface area of $100 \mathrm{~m}^{2} \mathrm{~g}^{-1}$ was used as support. It was crushed and sieved in order to retain grains with diameters between 0.1 and $0.25 \mathrm{~mm}$. Finally, the support was calcined for $4 \mathrm{~h}$ at $773 \mathrm{~K}$ under air (flowing $60 \mathrm{~cm}^{3} \mathrm{~min}^{-1}$ ) and then reduced with hydrogen for $4 \mathrm{~h}$ at $773 \mathrm{~K}$ (same flow-rate as above).

Hexachloroplatinic acid $\left(\mathrm{H}_{2} \mathrm{PtCl}_{6} .6 \mathrm{H}_{2} \mathrm{O}\right.$, Alfa Aesar) and rhodium (III) chloride $\left(\mathrm{RhCl}_{3} .3 \mathrm{H}_{2} \mathrm{O}\right.$, Johnson Matthey) were used for the preparation of monometallic and bimetallic catalysts, except for the organometallic grafting performed in organic medium, for which rhodium (III) acetylacetonate $\left(\mathrm{Rh}(\mathrm{acac})_{3} \text {, Alfa Aesar) and platinum (II) acetylacetonate (Pt(acac) }\right)_{2}$ Alfa Aesar) were chosen.

For all catalysts, the Rh and Pt nominal contents were of $0.5 \mathrm{wt} \%$ and $1.0 \mathrm{wt} \%$, respectively, which corresponds to the same atomic content.

Monometallic catalysts were prepared by simple impregnation. Different preparation techniques were used for bimetallic catalysts, namely coimpregnation, organometallic grafting and microsuspension.

\subsubsection{Preparation by coimpregnation (CI)}

The bimetallic catalyst named (PtRh)/CI was prepared by coimpregnation of hexachloroplatinic acid and rhodium chloride on the support.

In this procedure, $30 \mathrm{~mL}$ of water acidified by addition of hydrochloric acid and $1.5 \mathrm{~mL}$ of precursor salts were mixed. Then, the support was covered by the mixture and left one night under stirring. Water was then evaporated at $343 \mathrm{~K}$ and the catalyst was dried overnight at 393 $\mathrm{K}$, treated under air at $573 \mathrm{~K}$ during $4 \mathrm{~h}$ and then under flowing hydrogen at $573 \mathrm{~K}$ for $4 \mathrm{~h}$. 


\subsubsection{Preparation by Organometallic Grafting method (OG)}

Unlike the others, this preparation was carried out in organic media. This technique was based onto grafting of the second metal on the preformed Pt particles surface. The monometallic catalyst was prepared by impregnation of platinum 2,4-pentanedionate on alumina. The metal particle size of the parent monometallic catalyst is $\langle\mathrm{d}\rangle=2.0 \mathrm{~nm}$.

The preparation was carried out in a fixed-bed reactor equipped with an addition funnel, according to a procedure similar to the one described in [6]. After the pretreatment of $2.5 \mathrm{~g}$ of $\mathrm{Pt} / \mathrm{Al}_{2} \mathrm{O}_{3}$ under hydrogen at $673 \mathrm{~K}$ during $2 \mathrm{~h}$ to ensure the complete reduction of metal particles, $15 \mathrm{~mL}$ of toluene were introduced at ambient temperature on the catalyst under hydrogen for 5 minutes. Then, the solution was purged under nitrogen to remove the excess of hydrogen and $15 \mathrm{~mL}$ of a solution containing toluene and rhodium 2,4-pentanedionate $(0.97$ mmol. $\mathrm{dm}^{-3}$ of $\left.\mathrm{Rh}(\mathrm{acac})_{3}\right)$, previously purged, were introduced onto the catalyst. The mixture (catalyst and solution) was heated at $343 \mathrm{~K}$ under argon flow for $6 \mathrm{~h}$ with a cooling system at the top of the reactor to avoid the evaporation of toluene. After that, toluene was removed by filtration; the catalyst was dried under argon at $393 \mathrm{~K}$ and reduced under hydrogen flow at 473 K. This final catalyst was named Pt-Rh/OG.

\subsubsection{Preparation in Microsuspension (MS)}

The catalyst was prepared in microsupension following the procedure described by Venezia et al. [7]. The reaction was carried out in a water/ethanol mixture $(1: 1 \mathrm{v} / \mathrm{v})$ containing polyvinylpyrrolidone (PVP, MW: 10 000, Aldrich) as steric agent with a concentration of 3.75 mg.cm ${ }^{-3}$ and both chlorinated metallic salts with a total concentration of $0.75 \mathrm{mg} \cdot \mathrm{cm}^{-3}$. This solution was refluxed at $356 \mathrm{~K}$ overnight after introduction of the support at this temperature. Immediately, the suspension turned in dark due to metal reduction. The solvent was removed by centrifugation, and then the catalyst was washed five times with $50 \mathrm{~mL}$ of water and two 
times with $50 \mathrm{~mL}$ of ethanol and removed by centrifugation too. The efficiency of washes was checked by measuring the total organic carbon amount in remaining solution after each wash. The solid was finally dried at $343 \mathrm{~K}$ overnight. This catalyst was named (PtRh)/MS.

As the objective of the study was to compare the effect of the preparation methods, it was chosen to not calcine the samples for MS and OG methods since it is known that, for bimetallic particles, oxidizing treatments lead to an enrichment phenomenon or metal segregation, risking to mask the effect of the preparation method.

\subsection{Characterization}

\subsubsection{Determination of metal content}

The metal content was determined by ICP-OES (Perkin Elmer Optima 2000 DV) and X-ray fluorescence techniques (Bruker AXS S4 Explorer). Before ICP analysis, samples were mineralized in strong acids with microwave heating.

\subsubsection{Chemisorption of hydrogen}

The hydrogen chemisorption capacity was determined by a static volumetric vacuum technique at room temperature. First of all, the catalyst was cleaned under ultra high vacuum overnight to eliminate the adsorbed molecules. Then, the catalyst was reduced under 750 mbar of $\mathrm{H}_{2}$ at 573

$\mathrm{K}$ for $1 \mathrm{~h}$, and purged under vacuum until a low pressure $\left(\mathrm{P}<10^{-5} \mathrm{mbar}\right)$ was reached. Two series of hydrogen adsorption isotherms were performed with an increasing hydrogen pressure, from 10 mbar to 70 mbar with an increment of 10 mbar. Between the two series, the sample was submitted to ultrahigh vacuum in order to remove weakly bound hydrogen. The amount of adsorbed hydrogen was calculated by extrapolating the isotherm to $\mathrm{P}=0$. The first isotherm allows determining the total amount of adsorbed hydrogen and the second one the amount of physisorbed hydrogen. The amount of chemisorbed hydrogen was calculated by difference 
between these two values. The metal particle size was calculated considering a stoichiometry of $\mathrm{H} / \mathrm{M}=1$, and assuming that particles correspond to cubes deposited on the support and exposing 5 faces [8], with an equal distribution between (111), (110) and (100) planes.

\subsubsection{Adsorption of probe molecules followed by FTIR}

The adsorption of probe molecules on catalyst surface was followed by Fourier Transformed Infra-Red (FTIR) spectroscopy using a Nicolet 6700 FT-IR spectrometer. The catalyst was prepared in the form of a self-supported wafer of $15-20 \mathrm{mg}$ with a diameter of $16 \mathrm{~mm}$ and a surface of $2 \mathrm{~cm}^{2}$. This pellet was placed in a cell and reduced at $573 \mathrm{~K}$ for $1 \mathrm{~h}$ under $\mathrm{H}_{2}$ and purged at this temperature under vacuum $\left(\mathrm{P}<10^{-5} \mathrm{mbar}\right)$. Reference spectrum of the clean surfaces was then collected at room temperature (RT). The spectra of CO and/or NO adsorbed on the metal surface were obtained by subtraction of the reference spectrum to the collected spectrum after probe molecule adsorption. This allowed eliminating the influence of the characteristics of the sample, such as particle size and specific surface area of the support and density of the wafer [9].

\section{* Chemisorption of $\mathrm{CO}(\mathrm{CO} / \mathrm{FTIR})$}

After purging under ultra-high vacuum, $\mathrm{CO}$ was introduced in excess at RT to reach $27 \mathrm{mbar}$ of $\mathrm{CO}$ in the cell, which was checked to permit a full coverage of the metal surface by CO. Then, the sample was submitted to ultra high vacuum and a spectrum was recorded. In order to determine the accessibility of platinum in bimetallic catalysts, a calibration curve was used, obtained by using well-known monometallic platinum catalysts with various different dispersions, determined by hydrogen chemisorption and checked by TEM, and by measuring the corresponding surface area of the linear $\mathrm{CO}$ band. This allowed determining the molar extinction coefficient for linear CO adsorbed on Pt according to Beer's law [9].

\footnotetext{
* Chemisorption of NO, then CO (NO-CO/FTIR)
} 
After purging under ultra-high vacuum, $240 \mathrm{mbar}$ of $3 \% \mathrm{NO} / \mathrm{He}$ (corresponding to $15 \mathrm{mbar}$ of NO) in the cell were introduced on the sample heated at $473 \mathrm{~K}$. The pellet was maintained for $10 \mathrm{~min}$ at this temperature and was then placed under vacuum for $45 \mathrm{~min}$ at room temperature before taking a spectrum. Then, 27 mbar of $\mathrm{CO}$ was introduced for $3 \mathrm{~min}$. The gas was evacuated and another spectrum was collected. As previously performed for determining the molar extinction coefficient of linear $\mathrm{CO}$ on $\mathrm{Pt}$ for direct $\mathrm{CO}$ adsorption, calibrations curves were plotted after $\mathrm{NO}$ adsorption, for $\mathrm{Rh}$, and $\mathrm{NO}$ then $\mathrm{CO}$ adsorption for platinum, using rhodium and platinum monometallic catalysts of known dispersion values.

\subsubsection{Temperature Programmed Reduction}

Temperature programmed reduction (TPR) was carried out in a Micromeritics AutoChem II equipped with a CryoCooler II. First of all, the catalyst (200 mg) underwent an oxidation pretreatment during $1 \mathrm{~h}$ at $673 \mathrm{~K}$ under $\mathrm{O}_{2}$ and was flushed at the same temperature under $\mathrm{N}_{2}$ for $2 \mathrm{~h}$. Then, the catalyst was cooled to $253 \mathrm{~K}$ and hydrogen was passed on the catalyst up to $773 \mathrm{~K}$ and analyzed by GC.

\subsubsection{Transmission Electron Microscopy}

The sample was dispersed in ethanol and deposited on a copper grid. Then, particle shape and size were determined by Transmission Electron Microscopy (TEM) analysis (TEM/STEM JEOL 2100 UHR) with a resolution of $0.19 \mathrm{~nm}$. This apparatus was coupled with an energy dispersive X-ray spectrometer (EDX) used in the nanoprobe mode for the analysis of Pt and $\mathrm{Rh}$.

The particle size distribution was obtained from TEM pictures calculating the average particle diameter from the measurement performed on at minimum 100 particles.

\subsubsection{X-ray diffraction}


X-ray diffraction (XRD) measurements were performed at room temperature in a Bruker AXS D5005 X-ray diffractometer, working with CuK $\alpha$ radiation $(\lambda=1.54184 \AA)$, generated at 40 $\mathrm{kV}$ and $40 \mathrm{~mA}$. Signal is recorded for $2 \theta$ between $10^{\circ}$ and $90^{\circ}$ with a step of $0.04^{\circ}$ and a step time of 6 s. For sample identification, diffraction patterns were compared to the ICDD (International Center for Diffraction Data) database integrated in the EVA software.

\subsubsection{Catalytic tests}

\section{a. Cyclohexane dehydrogenation}

The cyclohexane dehydrogenation reaction was performed in a fixed-bed reactor at atmospheric pressure. $20 \mathrm{mg}$ of catalyst was reduced for $1 \mathrm{~h}$ at $573 \mathrm{~K}$ and the temperature was decreased to $543 \mathrm{~K}$ for reaction. Cyclohexane was injected using a calibrated motor-driven syringe $(0.03$ $\left.\mathrm{cm}^{3} \min ^{-1}\right)$ in a hydrogen flow $\left(60 \mathrm{~cm}^{3} \min ^{-1}\right)$. Gases were taken every 10 min for $2 \mathrm{~h}$ and analyzed by GC with a flame ionization detector (Varian 3400X) on a HP-PLOT $\mathrm{Al}_{2} \mathrm{O}_{3}$ "KCl" column. The only detected product was benzene.

\section{b. Methylcyclopentane ring-opening}

Methylcyclopentane (MCP) ring-opening reaction was performed in a fixed-bed reactor at atmospheric pressure. Before the reaction, $135 \mathrm{mg}$ of catalyst were reduced with $\mathrm{H}_{2}$ at $773 \mathrm{~K}$ for $1 \mathrm{~h}$. The conditions used were: $\mathrm{H}_{2}$ flow rate $=36 \mathrm{~cm}^{3} \mathrm{~min}^{-1}, \operatorname{MCP}($ liq $)$ flow $=0.362 \mathrm{~cm}^{3}$ $\mathrm{h}^{-1}$, reaction temperature $=533 \mathrm{~K}$, reaction time $=2 \mathrm{~h}$. The reaction products were analyzed on a Varian CX 3400 gas chromatograph after separation on a PONA column.

\section{Results and discussion}

\subsection{TEM and $\mathrm{H}_{2}$ chemisorption}


For all catalysts, the measured actual composition corresponds to the nominal values, i.e. $0.5 \pm$ 0.1 wt.\% of Rh and $1.0 \pm 0.2$ wt.\% of Pt (Table 1 ).

Table 1 shows that the $\mathrm{H} / \mathrm{M}$ ratio varies according to the preparation method. The (PtRh)/CI sample presents the best dispersion leading to $\mathrm{d}=1.3 \mathrm{~nm}$, whereas $\mathrm{Pt}-\mathrm{Rh} / \mathrm{OG}$ and $(\mathrm{PtRh}) / \mathrm{MS}$ present diameters higher than $3.0 \mathrm{~nm}$. The small size of CI catalyst may be linked to the presence of hydrochloric acid [4], which may play an essential role in metallic dispersion because chloride ions may compete with precursor adsorption during coimpregnation procedure, and increase the platinum and rhodium dispersion on alumina [10]. For the CI catalyst, the size determined from the $\mathrm{H} / \mathrm{M}$ values corresponds to the one measured on the TEM pictures (Fig.1a), whereas for the two others (Figs.1b and 1c), the size deduced from TEM pictures is lower than the one determined from chemisorption experiments. The large particle size obtained with the OG technique is directly linked to the preparation procedure, which involves an enlargement of particles size by deposition of rhodium on the preformed platinum particles with an initial diameter of $1.3 \mathrm{~nm}$. In this sample, the analysis by EDX showed that small particles are composed of both $\mathrm{Pt}$ and $\mathrm{Rh}$, and then are bimetallic, with a composition around the nominal composition (Pt/Rh around 50/50), whereas the largest ones are richer in platinum. This result is consistent with the preparation procedure, since the accessibility of small particles, which are majority on this sample, is higher than the one of large particles. Consequently, there was more Rh deposited on small Pt particles than on the largest ones. For (PtRh)/MS, the overestimation of the particle size as calculated from $\mathrm{H}_{2}$ chemisorption results may be due to the presence of some polymer (polyvinylpyrrolidone) residues at the particle surface, which decreases the chemisorption capability. The presence of the polymer is evidenced by characteristic bands in infrared spectra (Fig. 2) performed before and after reduction. In the literature [11], spectrum of pure polyvinylpyrrolidone has shown 6 series of bands: one at $3500 \mathrm{~cm}^{-1}$ corresponding to the stretching vibration of water, two at 2910 and 
$2960 \mathrm{~cm}^{-1}$ attributed to stretching of $\mathrm{CH}_{2}$ or $\mathrm{CH}$ groups, one at $1660 \mathrm{~cm}^{-1}$ corresponding to stretching vibration of carbonyl group $(\mathrm{C}=\mathrm{O})$ and two at 1460 and $1430 \mathrm{~cm}^{-1}$ for bending vibration of $\mathrm{CH}_{2}$. As shown in Fig. 2 before and after reduction of (PtRh)/MS, a shift of the vibration band corresponding to carbonyl to lower wavenumber $\left(\approx 1600 \mathrm{~cm}^{-1}\right)$ is observed, which may be explained by the adsorption of the carbonyl function on particle surface, the small peak at $1660 \mathrm{~cm}^{-1}$ being attributed to the carbonyl function of free PVP [12]. It can be also seen that the reduction modifies some bands, especially those attributed to water, $\mathrm{CH}_{2}$ and $\mathrm{C}-\mathrm{N}$ vibrations, but the band corresponding to carbonyl adsorbed on the metal function is still present. For the MS sample, the EDX analysis demonstrated that all the particles are bimetallic with a composition similar to the nominal one. On the contrary, on the CI sample, in some places monometallic Pt particles were identified, whereas in other places, Rh and Pt were analyzed together.

\subsection{Temperature programmed reduction by $\mathrm{H}_{2}$}

To characterize Pt-Rh interactions, temperature programmed reduction studies were carried out on catalysts preoxidized at $673 \mathrm{~K}$. If platinum and rhodium are in strong interaction, the metal oxide that is reduced at the lowest temperature may catalyze the reduction of the other one and permits to decrease its reduction temperature [13-15]. In Fig. 3, TPR profiles of bimetallic catalysts are compared to those of the corresponding chlorinated (for CI and MS bimetallic catalysts) and non-chlorinated (for OG bimetallic catalyst) monometallic catalysts. Monometallic $\mathrm{Rh}$ catalysts are reduced at lower temperature compared to their monometallic Pt counterparts, since Rh and Pt catalysts prepared with organic precursors present a maximum of reduction peak at 343 and $383 \mathrm{~K}$, respectively, and the $\mathrm{Rh}$ and $\mathrm{Pt}$ ones prepared with chlorinated salts at 451 and $493 \mathrm{~K}$, respectively. The higher reduction temperature observed for catalysts prepared from chlorinated precursors may be explained by the lower reducibility of oxychloride species in stronger interaction with the support compared to the oxide species. For 
(PtRh)/CI catalyst (Fig. 3d), two reduction peaks are detected: one at $388 \mathrm{~K}$ with a much higher $\mathrm{H}_{2}$ consumption compared to the second one at $498 \mathrm{~K}$. In comparison with $\mathrm{Pt}$ and $\mathrm{Rh}$ monometallic catalysts (Fig. 3f and 3g), the first peak may be attributed to the reduction of rhodium oxide alone with a small part of platinum oxide, but as the reduction temperature is lower than that of the monometallic chlorinated $\mathrm{Rh}$, these species are probably in weak interaction with alumina. The second peak at high temperature may be attributed to the reduction of platinum oxychloride. This result indicates that only a small part of $\mathrm{Pt}$ and $\mathrm{Rh}$ atoms are in contact, in line with the preparation method that favors the random deposition of $\mathrm{Pt}$ and $\mathrm{Rh}$ precursors on alumina. For Pt-Rh/OG (Fig. 3c), only one single peak is present at $343 \mathrm{~K}$, at a temperature similar to that of the reduction of Rh (Fig. 3a), and the hydrogen consumption corresponds to the amount needed to completely reduce the rhodium and platinum oxides, proving the strong interaction between rhodium and platinum atoms. These results confirm that this preparation method favors the preferential deposition of rhodium on platinum particles and not on the alumina support, in agreement with the literature $[6,16,17]$. For (PtRh)/MS (Fig. 3e), the TPR profile displays two reduction peaks, a large one at $284 \mathrm{~K}$ and a small one at $750 \mathrm{~K}$, with a $\mathrm{H}_{2}$ consumption indicating a total reduction of both oxides. It should be noted that monometallic Rh and Pt catalysts, prepared in the same conditions as (PtRh)/MS, show reduction peaks at $331 \mathrm{~K}$ and $268 \mathrm{~K}$, respectively (results not shown). These reduction temperatures are much lower than those of the monometallic catalysts prepared by impregnation. This may be explained by the low metal-support interaction resulting from the preparation method, consisting in the reduction of the metal precursor in suspension in the presence of a polymer and the subsequent deposition on the support. The main reduction peak of the bimetallic (PtRh)/MS catalyst is between those of the two corresponding monometallic catalysts, characteristic of the co-reduction of $\mathrm{Pt}$ and $\mathrm{Rh}$, indicating that these two metals are present in the same metal nanoparticles. 
In conclusion, from TPR results it was shown that $\mathrm{Pt}$ and $\mathrm{Rh}$ are together in bimetallic particles for catalysts prepared by organometallic grafting and microsuspension, whereas they are present in both mono and bimetallic particles for catalyst prepared by coimpregnation.

\subsection{Characterization by XRD}

XRD analysis was used for characterizing all the samples but given the low amount of metal and the small particle size, only the alumina support was detected. For the MS sample, the metal particles were also analyzed before their deposition on the support. The XRD pattern, reported in Fig. 4, demonstrates that particles are probably made up of PtRh alloy and then in strong interaction, thus confirming the results obtained by TPR.

\subsection{CO/FTIR on Pt, Rh and Pt-Rh supported catalysts}

$\mathrm{CO}$ is widely employed as probe molecule to characterize Pt alumina catalysts. By infrared spectroscopy, two series of bands are detected [18-21]. The first one near 2095-2000 $\mathrm{cm}^{-1}$ corresponds to linear $\mathrm{Pt}^{0}-\mathrm{CO}$ and the other one, between 1800 and $1875 \mathrm{~cm}^{-1}$, corresponds to bridged species $\mathrm{Pt}^{0}{ }_{\mathrm{x}}-\mathrm{CO}$. As more than $95 \%$ of $\mathrm{CO}$ is linearly bonded to $\mathrm{Pt}^{0}$, the accessibility of platinum can be determined from the molar extinction coefficient determined from this linear CO band. In our case, this coefficient was $0.315 \mathrm{~cm} . \mu \mathrm{mol}^{-1}$. The frequency of this band depends on the Pt atoms position at the particle surface (on various types of faces, on edge or corner) and increases with the coordination number of platinum [18-21]. A summary is shown in Table 2.

For Rh catalysts supported on alumina, in addition to the bands corresponding to CO linearly and bridged bonded to $\mathrm{Rh}^{0}$, two others bands are identified and attributed to symmetric and anti-symmetric gem-dicarbonyl species on $\mathrm{Rh}^{+\mathrm{I}}\left(\mathrm{Rh}^{\mathrm{I}}-(\mathrm{CO})_{2}\right)$ [22]. The presence of $\mathrm{Rh}^{+\mathrm{I}}$ is explained by the oxidation of $\mathrm{Rh}^{0}$ in the presence of $\mathrm{CO}$ involving hydroxyl groups of the alumina support ${ }^{23}$ due to the migration of $\mathrm{Rh}$ onto the support in the presence of $\mathrm{CO}$. The 
positions of these various bands are also summarized in Table 2 . $\mathrm{The}^{\mathrm{Rh}}-(\mathrm{CO})_{2} / \mathrm{Rh}^{0}-\mathrm{CO}$ ratio fluctuates with rhodium particle size and also with contact time with CO. Therefore, contrary to platinum, there is no linear dependence between the amount of $\mathrm{CO}$ linearly bound to $\mathrm{Rh}^{0}$ and the rhodium dispersion, with no possibility to accurately determine the amount of Rh atoms at the metal particle surface. Thus, for bimetallic $\mathrm{PtRh} / \mathrm{Al}_{2} \mathrm{O}_{3}$ catalysts, only the amount of $\mathrm{CO}$ adsorbed on Pt can be determined, after decomposition of the spectra, and the band frequencies may give information on the platinum location on metallic surface. Another problem for bimetallic catalysts is that there is an overlap of bands corresponding to linear $\mathrm{CO}$ adsorbed on $\mathrm{Pt}^{0}$ or $\mathrm{Rh}^{0}$ between 2070 and $2040 \mathrm{~cm}^{-1}$. In the following, only bands at frequencies higher than $2070 \mathrm{~cm}^{-1}$ will be unambiguously attributed to $\mathrm{Pt}^{0}-\mathrm{CO}$. Another band, around $2060 \mathrm{~cm}^{-1}$ may be attributed to $\mathrm{CO}$ adsorbed on Pt alloyed with Rh, according to Lévy et al. [5].

As shown in Fig. 5, the spectra are deeply different depending on the preparation method used for obtaining bimetallic catalysts. On the three catalysts, after decomposition of the spectra with a Gaussian function, bands corresponding to $\mathrm{Pt}^{0}-\mathrm{CO}$, around $2081 \pm 2 \mathrm{~cm}^{-1}$, and $\mathrm{Rh}^{+1}-(\mathrm{CO})_{2}$, around 2025 and $2100 \mathrm{~cm}^{-1}$, are clearly identified. Also, one band at $2069 \pm 2 \mathrm{~cm}^{-1}$ which could be attributed either to $\mathrm{Pt}^{0}-\mathrm{CO}$ or to $\mathrm{Rh}^{0}-\mathrm{CO}$ is observed for the three catalysts. In the case of the (PtRh)/CI catalyst (Fig. 5a) one band is observed at $2054 \mathrm{~cm}^{-1}$, which could correspond to $\mathrm{Rh}^{0}$ $\mathrm{CO}$ or $\mathrm{Pt}^{0}-\mathrm{CO}$. An additional band is detected at $2060 \pm 2 \mathrm{~cm}^{-1}$ for $(\mathrm{PtRh}) / \mathrm{MS}$ and $\mathrm{Pt}-\mathrm{Rh} / \mathrm{OG}$ catalysts, which may be attributed to the linear $\mathrm{CO}$ adsorption on one Pt atom alloyed with $\mathrm{Rh}$ $[3,5]$. This is in accordance with the preparation methods used favoring Pt-Rh interactions and with TPR results. As proposed by Lévy et al.[5], the molar extinction coefficient of $\mathrm{Pt}^{0}-\mathrm{CO}$ after $\mathrm{CO}$ adsorption was used to quantify the number of Pt atoms constituting the Pt-Rh alloy at the surface. Due to the complexity of the spectra obtained for bimetallic catalysts, the direct quantification was performed only for peaks clearly corresponding to $\mathrm{Pt}$ alone $\left(2081 \mathrm{~cm}^{-1}\right)$ or in alloys $\left(2060 \mathrm{~cm}^{-1}\right)$. The amount of the other species leading to the other observed bands was 
quantified by difference, using the total amount of accessible metals as determined by chemisorption of $\mathrm{NO}$ and then $\mathrm{CO}$, followed by FTIR, which will be discussed in the following paragraph. One have to keep in mind that these other species may correspond either to rhodium (vibrations of $\mathrm{Rh}(\mathrm{CO})_{2}$ identified on the 3 catalysts), or to platinum or rhodium, since it was impossible to unambiguously attribute the bands at 2054 and $2069 \mathrm{~cm}^{-1}$ to $\mathrm{Pt}^{0}-\mathrm{CO}$ or $\mathrm{Rh}^{0}-\mathrm{CO}$. The results are reported in Table 3. It can be seen that the amount of Pt alloyed with $\mathrm{Rh}$ is more significant for the Pt-Rh/OG than for $(\mathrm{PtRh}) / \mathrm{MS}$. Also, one has to keep in mind that the Pt$\mathrm{Rh} / \mathrm{OG}$ catalyst was prepared by deposition of $\mathrm{Rh}$ atoms on monometallic $\mathrm{Pt}$ particles by organometallic grafting. As the amount of added Rh atoms is much higher than the amount of accessible Pt atoms, i.e. Pt atoms at the surface, after preparation the Pt surface should be completely covered by a Rh overlayer. As CO adsorption followed by FTIR has demonstrated that $\mathrm{Pt}$ is present at the surface of the bimetallic particles, it means that some Pt atoms were not covered by Rh during the preparation.

\subsection{NO-CO/FTIR on Pt, Rh and Pt-Rh supported catalysts}

At moderate temperature, $\mathrm{NO}$ is able to completely oxidize $\mathrm{Rh}^{0}$ to $\mathrm{Rh}^{+1}$ and leads to the formation of $\mathrm{Rh}^{\mathrm{I}}-\mathrm{NO}^{+}$. Thus, its FTIR spectrum presents a characteristic vibration band completely isolated from the others [23]. Hence, it is possible to determine the quantity of rhodium at the surface of metallic particles by $\mathrm{NO}$ adsorption. In addition, $\mathrm{CO}$ adsorption may be carried out after NO adsorption to characterize the platinum surface. According to the literature, many NOx species adsorbed on rhodium or on alumina may be observed by FTIR, as shown in Table 4.

In the present study, the NO adsorption at $473 \mathrm{~K}$, temperature used by Lévy et al. [5] to oxidize all rhodium in the $+\mathrm{I}$ state at the surface, was at first studied on Rh monometallic catalyst with 
various contact time to follow the evolution of adsorbed NOx species as a function of time. As shown in Fig. 6, after a short exposure time to $\mathrm{NO}$ at $473 \mathrm{~K}$, between 5 and $11 \mathrm{~min}$, a large and isolated band at $1910 \mathrm{~cm}^{-1}$, attributed to $\mathrm{Rh}^{\mathrm{I}}-\mathrm{NO}^{+}$formation, is observed accompanied with multiple bands in the $1800-1400 \mathrm{~cm}^{-1}$ range, corresponding to NOx species on alumina. For longer times, these latter bands increase considerably, and are associated with a smaller band corresponding to $\mathrm{Rh}^{\mathrm{I}}-\mathrm{NO}^{+}$species, which decreases as a function of time. The reaction between NO and the oxygen of the alumina support leads to the formation of nitrates/nitrites. Consequently, the experimental conditions, especially the contact time, were chosen in order to avoid formation of nitrates as far as possible. Therefore, the molar extinction coefficient was determined after 10 min of contact time from $\mathrm{Rh}^{\mathrm{I}}-\mathrm{NO}^{+}$band using $\mathrm{Rh} / \mathrm{Al}_{2} \mathrm{O}_{3}$ catalysts with various dispersions. This coefficient was equal to $0.237 \mathrm{~cm} . \mu \mathrm{mol}^{-1}$. Moreover, it is important to note that, when this exposure to $\mathrm{NO}$ is followed by an exposure to $\mathrm{CO}$ at room temperature, a new band may appear at $2115-2130 \mathrm{~cm}^{-1}$ corresponding to $\mathrm{Rh}^{2+}-\mathrm{CO}$ species [24] showing that, in some cases, $\mathrm{NO}$ oxidizes $\mathrm{Rh}^{0}$ not only to $+\mathrm{I}$ state but also to $+\mathrm{II}$ oxidation state (Fig. 7). As shown in this figure, after $\mathrm{CO}$ adsorption, spectrum shows also rhodium gem-dicarbonyl species at $2030 \mathrm{~cm}^{-1}$ (antisymmetric gem-dicarbonyl) and $2100 \mathrm{~cm}^{-1}$ (symmetric gemdicarbonyl), and the linear NO band adsorbed on $\mathrm{Rh}^{+\mathrm{I}}$ decreases proportionally. Linear adsorption of $\mathrm{CO}$ on $\mathrm{Rh}^{0}$ is not observed, proving that all $\mathrm{Rh}^{0}$ species were oxidized during the treatment under NO.

Contrary to rhodium, the oxidation of $\mathrm{Pt}$ to $\mathrm{Pt}^{\delta+}$ by $\mathrm{NO}$ is difficult at $473 \mathrm{~K}$. NO adsorption on $\mathrm{Pt}$ atoms may form linear $\mathrm{Pt}^{0}-\mathrm{NO}$ and non-linear $\mathrm{Pt}^{0}-\mathrm{NO}$ species [25], at respectively 1750 $1760 \mathrm{~cm}^{-1}$ and $1400-1650 \mathrm{~cm}^{-1}$. Freysz et al.[26] observed linear $\mathrm{Pt}^{0}-\mathrm{NO}$ at $1797 \mathrm{~cm}^{-1}$ and another species at $1833 \mathrm{~cm}^{-1}$ attributed to $\mathrm{Pt}^{\delta+}$-NO species. On $\mathrm{Pt} / \mathrm{Al}_{2} \mathrm{O}_{3}$ after contact with $\mathrm{NO}$, only bands attributed to the formation of nitrates and nitrites on alumina are observed (Fig. 8). When CO is introduced in the cell, a new band appears in the $2000-2100 \mathrm{~cm}^{-1}$ range, 
corresponding to $\mathrm{Pt}^{0}-\mathrm{CO}$ species. The molar extinction coefficient determined for this $\mathrm{Pt}^{0}-\mathrm{CO}$ band after NO-CO adsorption is equal to $0.114 \mathrm{~cm} . \mu \mathrm{mol}^{-1}$. This coefficient is three times smaller than the one determined after direct $\mathrm{CO}$ adsorption, as also observed by Lévy et al.[5]. Moreover, for $\mathrm{Pt} / \mathrm{Al}_{2} \mathrm{O}_{3}$ catalyst, a band at $2115-2150 \mathrm{~cm}^{-1}$ may also be detected corresponding to $\mathrm{Pt}^{2+}-\mathrm{CO}$ species [24], which is not observed in the present case (Fig. 8).

Thus, the advantages of submitting a Pt-Rh catalyst to NO at moderate temperature and then to $\mathrm{CO}$ at room temperature, are that (i) there is not $\mathrm{Pt}^{0}-\mathrm{NO}$ band superimposed with that of $\mathrm{Rh}^{\mathrm{I}}-$ $\mathrm{NO}^{+}\left(1910 \mathrm{~cm}^{-1}\right)$ and (ii) there is not $\mathrm{Rh}^{0}-\mathrm{CO}$ band interfering with that of $\mathrm{Pt}^{0}-\mathrm{CO}$, thus favoring the quantification of $\mathrm{Rh}$ and $\mathrm{Pt}$ species at the particle surface.

As shown in Fig. 9, the Pt- $\mathrm{Rh} / \mathrm{Al}_{2} \mathrm{O}_{3}$ spectra after NO and NO-CO adsorption are deeply different depending on the bimetallic catalysts. The quantification of rhodium at the surface was deduced from $\mathrm{Rh}^{\mathrm{I}}-\mathrm{NO}^{+}$band after $\mathrm{NO}$ adsorption $\left(1910 \mathrm{~cm}^{-1}\right)$ and that of platinum from the $\mathrm{Pt}^{0}-\mathrm{CO}$ band after NO-CO adsorption $\left(2000-2100 \mathrm{~cm}^{-1}\right)$. Results (Table 3) for the amount of $\mathrm{Pt}$ alone obtained from NO-CO/FTIR are similar to those obtained from CO/FTIR considering the same global metal accessibility. However, the band attributed to Pt alloyed with Rh has disappeared from the spectra of (PtRh)/MS and Pt-Rh/OG. This may be due to a surface enrichment by $\mathrm{Rh}$ at the expense of $\mathrm{Pt}$ in the $\mathrm{Pt}-\mathrm{Rh}$ alloyed entities, in the presence of $\mathrm{NO}$ at $473 \mathrm{~K}$ [5]. These Pt species in strong interaction with Rh, correspond to Pt surrounded by $\mathrm{Rh}$, at the surface and subsurface layer. It means that an exchange of this type of Pt atom at the surface with one $\mathrm{Rh}$ atom at the subsurface is sufficient to perform the enrichment and lead to the disappearance of the Pt atom from the surface. This driven force of this enrichment phenomenon is due to the much stronger Rh-O bond strength compared to the Pt-O one, the oxygen originating from NO adsorption and dissociation [27]. The free oxygen atoms, can access $\mathrm{Rh}$ atoms in the first two layers, drawing them to the surface [28]. It was shown that this reconstruction only affects the two first atom layers, the surface layer being composed of mainly 
$\mathrm{Rh}$, the second one being Pt enriched [29]. The segregation of Rh under oxidizing conditions for Pt-Rh bimetallic catalysts is a very well known phenomenon, which has been the subject of many studies [27-36]. It is also often explained by the higher stability of rhodium oxides compared to the one of platinum oxides $[31,33]$. Consequently, it can be inferred that the surface composition determined after oxidation under $\mathrm{NO}$ and then $\mathrm{CO}$ chemisorption, is characteristic of the surface under oxidizing conditions, whereas the one determined directly after reduction and then $\mathrm{CO}$ adsorption will be more in accordance with the surface composition under reducing conditions.

\subsection{Cyclohexane dehydrogenation and methylcyclopentane ring opening}

Catalysts were evaluated in cyclohexane dehydrogenation and methylcyclopentane ringopening. Results are reported in Table 5.

For cyclohexane dehydrogenation, the nature of the metal is a crucial parameter for the catalytic activity [37]. The results of cyclohexane dehydrogenation of the mono and bimetallic catalysts

(Table 5) show that the Turn-Over Frequency (TOF) value measured on the platinum catalyst are higher than the one obtained on rhodium, in agreement with results of the literature [2,24,38]. As TOF values for the bimetallic catalysts are between the values of the monometallic $\mathrm{Rh}$ and $\mathrm{Pt}$ catalysts, this indicates that both metals are at the surface of the metal particles, in accordance with the results obtained by FTIR of CO or NO-CO (Table 3). Taking into account the amount of $\mathrm{Pt}$, alone or alloyed with $\mathrm{Rh}$, as determined directly by $\mathrm{CO}$ chemisorption followed by FTIR, and considering that Pt-Rh interaction has a negligible effect on the activity of Pt or Rh atoms for cyclohexane dehydrogenation, TOF values of the bimetallic catalysts can be calculated by linear combination of the TOF values of the corresponding monometallic catalysts modulated by the proportion of $\mathrm{Pt}$ and $\mathrm{Rh}$ at the particle surface [39]. 
The calculated TOF values are similar to the experimental ones for (PtRh)/CI and Pt-Rh/OG catalysts, thus validating for these catalysts the surface composition determined by FTIR of probe molecules. On the contrary, for the (PtRh)/MS catalyst the TOF value is higher than the experimental one, $0.51 \mathrm{~s}^{-1}$ against $0.33 \mathrm{~s}^{-1}$. This may be explained by the much lower metal accessibility, as determined from FTIR results $\left(9.4 \mu \mathrm{mol} \mathrm{g}^{-1}\right)$ compared to the one determined by chemisorption of hydrogen $\left(32.2 \mu \mathrm{mol} \mathrm{g}^{-1}\right)$, which was also lower than the one deduced from TEM pictures. Consequently, the quantitative metal distribution at the surface determined using probe molecules should be considered with caution for the (PtRh)/MS catalyst, for which polymer remains at the metal particle surface, probably disrupting the adsorption capacity of the metallic particles.

Methylcyclopentane selective ring opening is a reaction that was initially studied to characterize the metal function [40]. At low conversion, the formation of ring-opening products (ROP), namely n-hexane (nC6), 2-methylpentane (2MP) and 3-methylpentane (3MP) is favored. Other reactions may occur such as ring enlargement by isomerization, and then the production of cyclohexane that may be dehydrogenated to benzene, and cracking or deep hydrogenolysis, yielding $\mathrm{C} 1$ to $\mathrm{C} 5$ molecules. When the conversion increases, the selectivity to ROP decreases and among monometallic catalyst, iridium is the most active and selective one, since it allows maintaining high ROP selectivity for high MCP conversions [41] contrary to the other tested metals. Also for high MCP conversions, Rh is more active than $\mathrm{Pt}$ but both present low ROP selectivities [2]. Results, displayed in Table 5, obtained with monometallic catalysts, confirm that $\mathrm{Rh}$ presents higher $\mathrm{C}-\mathrm{C}$ breaking activity than $\mathrm{Pt}[2,42]$, with a TOF $\sim 3$ times higher. The bimetallic catalyst prepared by coimpregnation presents an activity roughly similar to that of the monometallic Rh catalyst. Surprisingly, the Pt-Rh/OG and (PtRh)/MS catalysts present TOF values much superior to those of the monometallic catalysts. High TOF values for bimetallic catalysts, higher than those of the two monometallic catalysts, were already observed [4] for 
Pt-Rh systems on alumina support, for MCH ring opening at high pressure, but only for very high $\mathrm{Rh}$ contents $(\mathrm{Pt} / \mathrm{Rh} \approx 0.17$, corresponding to 0.6 wt.\% of $\mathrm{Pt}$ and 0.85 wt.\% of $\mathrm{Rh})$. For lower Rh contents, TOF values were between those of the two reference catalysts, as for the (PtRh)CI catalyst. It was observed in this study that this latter catalyst presented the weakest interactions between $\mathrm{Pt}$ and $\mathrm{Rh}$, with the presence of monometallic particles, as characterized by TPR. As far as the formation of Ring-Opening Products (ROP) is concerned, the selectivity to ROP is higher for bimetallic catalysts than for the monometallic ones. The most selective catalysts are $\mathrm{Pt}-\mathrm{Rh} / \mathrm{OG}$ and $(\mathrm{PtRh}) / \mathrm{MS}$, the two catalysts for which the presence of $\mathrm{Pt}-\mathrm{Rh}$ alloy species, favoring high ROP selectivities [4], was demonstrated by CO-FTIR. It is known [43] that the selective ring opening of MCP may occur according to (i) a selective mechanism, leading only to 2-methylpentane (2MP) and 3-methylpentane (3MP), with $2 \mathrm{MP} / 3 \mathrm{MP}=2$, without n-hexane (nC6) (ii) a statistical mechanism, where the probability of breaking an endocyclic $\mathrm{C}-\mathrm{C}$ bond is independent of its position, leading to a statistical product distribution, with $2 / 5$ of nC6, 2/5 of $2 \mathrm{MP}$ and $1 / 5$ of $3 \mathrm{MP}$, and (iii) a partly selective mechanism, intermediate between the two previous ones. In the present study, a selective RO reaction occurs only on Pt-Rh/OG and (PtRh)/MS, for which the formation of nC6 is negligible and 2MP/3MP $\approx 2$. Monometallic Pt catalyst opens MCP via a statistical mechanism, according to the results of the literature $[4,44,45]$, whereas $\mathrm{Rh}$ monometallic catalyst and the bimetallic CI catalyst are partly selective. In conclusion, the formation of bimetallic $\mathrm{Pt}-\mathrm{Rh}$ particles with very strong interactions, forming $\mathrm{Pt}-\mathrm{Rh}$ alloys as identified by CO-FTIR during the preparation by organometallic grafting and microsuspension, leads to very selective catalysts for MCP ringopening.

\section{Conclusion}


Bimetallic Pt-Rh catalysts supported on alumina were prepared by three different ways, namely coimpregnation (CI), organometallic grafting (OG) and microsuspension (MS), these latter two methods favoring the formation of bimetallic entities. The better dispersion associated with the weakest $\mathrm{Pt}-\mathrm{Rh}$ interaction was obtained with the catalyst prepared by coimpregnation, which is composed by monometallic and bimetallic particles. Lower metal accessibilities were obtained for the two other bimetallic catalysts, but in this case, the presence of strong Pt-Rh interaction was identified by TPR. For the catalyst prepared by the colloidal route, even being carefully washed, some stabilizing polymer remains at the metal particle surface, which slightly hinders chemisorption of molecules such as $\mathrm{H}_{2}, \mathrm{CO}$ and NO. For this reason, the chemisorption of $\mathrm{CO}$ or NO-CO followed by FTIR gives only partial information on the surface composition for this catalyst. However, under $\mathrm{CO}$, the presence of bimetallic entities, corresponding to Pt alloyed with rhodium, i.e. surrounded by $\mathrm{Rh}$, was evidenced. These $\mathrm{Pt}-\mathrm{Rh}$ entities are also present in the bimetallic catalyst prepared by organometallic grafting. Two conclusions can be drawn from the results for cyclohexane dehydrogenation. In one hand, Pt and Rh interaction does not play a role in the activity of the catalysts for this reaction, as expected. On the other hand, the calculated TOF is in agreement with the experimental one for the CI and OG catalysts, validating the FTIR results. This calculated TOF is obtained from amount of surface Pt and Rh atoms determined by FTIR and based on the individual performances from monometallic catalysts. The performances of the catalysts for MCP ring-opening showed that, in agreement with previous results, the presence of strong Pt-Rh interactions, evidenced at the surface of bimetallic particles for the OG and MS catalysts, favors high selectivity to ring-opening products, and in addition, increases the TOF value compared to the one of the monometallic catalysts. In conclusion, controlled preparation of bimetallic catalysts by organometallic grafting or microsuspension leads to strong Rh-Pt interactions, which favor high activity and selectivity for methylcyclopentane ring-opening. 


\section{Acknowledgments}

The authors gratefully acknowledge the ECOS-MINCyT program n॰ A12E02 (2013-2015) which allowed the collaboration between the two research teams. N.H. acknowledges the Region Poitou-Charentes for its financial support.

\section{References}

[1] Z. Hu, Chem. Comm., (1996) 879-880.

[2] P. Samoila, M. Boutzeloit, C. Especel, F. Epron and P. Marécot, Appl.Catal. A: General, 369 (2009) 104-112.

[3] P. Samoila, M. Boutzeloit, C. Especel, F. Epron and P. Marécot, J. Catal., 276 (2010) $237-248$.

[4] P. Samoila, F. Epron, P. Marécot and C. Especel, Appl. Catal. A: General, 462-463 (2013) 207-219.

[5] P. J. Lévy, V. Pitchon, V. Perrichon, M. Primet, M. Chevrier and C. Gauthier, J. Catal., 178 (1998) 363-371.

[6] M. Chamam, K. Lázár, L. Pirault-Roy, I. Boghian, Z. Paál and A. Wootsch, Appl. Catal. A: General, 332 (2007) 27-36.

[7] A.M Venezia, V La Parola, G Deganello, B Pawelec, J.L.G Fierro, J. Catal., 215 (2003) $317-325$.

[8] G.C. Bond, Surf. Sci., 156 (1985) 966-981.

[9] M. Primet, M. El Azhar, R. Frety, M. Guenin, Appl. Catal., 59 (1990) 153-163.

[10] L. Ali, A.-G. Ali, S. Aboul-Fotouh and A. Aboul-Fotouh, Appl. Catal. A: General, 205 (2001) 129-146. 
[11] W. Tu, T. Hou, K. Qi, D. Chen and S. Cao, Coll. Surf. A: Physicochem. Eng.Asp., 428 (2013) 47-52.

[12] Y. Borodko, S.E. Habas, M. Koebel, P. Yang, H. Frei, G.A. Somorjai, J. Phys.Chem. B, 110 (2006) 23052-23059.

[13] T. Gjervan, R. Prestvik, B. Tøtdal, C. E. Lyman and A. Holmen, Catal. Today, 65 (2001) 163-169.

[14] A. Tanksale, J. Beltramini, J. Dumesic and G. Lu, J. Catal., 258 (2008) 366-377.

[15] J. H. A. Martens and R. Prins, Appl.Catal., 46 (1989) 31-44.

[16] J. L. Margitfalvi, I. Borbáth, E. Tfirst and A. Tompos, Catal. Today, 43 (1998) 29-49.

[17] M. Chamam, A. Wootsch, L. Pirault-Roy, I. Boghian and Z. Paál, Catal. Comm., 8 (2007) 686-692.

[18] P. Gardner, R. Martin, M. Tüshaus and A. M. Bradshaw, J. Electron Spectro. Related Phenomena, 54/55 (1990) 619-626.

[19] R. Greenler and K. Burch, Surf. Sci., 152/153 (1985) 338-345.

[20] A. Garnier, S. Sall, F. Garin, M. J. Chetcuti and C. Petit, J. Mol. Cat. A: Chem., 373(2013) 127-134.

[21] C. W. Olsen and R. J. Masel, Surf. Sci., 201(1988) 444-460.

[22] R. Dictor, Journal of Catalysis, 109(1988) 89-99.

[23] H.F.J. Van’t Blik, J.B.A.D. Van Zon, T. Hulzinga, J.C. Vis, J.C. Koningsberger, R. Prins, J. Phys. Chem. 87 (1983) 2264

[24] E. Rogemond, N. Essayem, R. Frety, V. Perrichon, M. Primet, M. Chevrier, C. Gauthier and F. Mathis, J. Catal., 186 (1999) 414-422.

[25] P. S. Dimick, J. L. Kross, E. G. Roberts, R. G. Herman, H. G. Stenger and C. E. Lyman, Applied Catalysis B: Environmental, 89 (2009) 1-11. 
[26] J.-L. Freysz, J. Saussey, J.-C. Lavalley and P. Bourges, Journal of Catalysis, 197 (2001) $131-138$.

[27] B.E. Nieuwenhuys, Advances in Catalysis, 44 (1999) 259-328

[28] P.A.J. Bagot, A. Cerezo, G.D.W. Smith, Surf. Sci. 601 (2007) 2245-2255.

[29] C.P. Oliver, B.V. King, D.J. O’Connor, Surf. Sci. 561 (2004) 33-42.

[30] T. Wang, L.D. Schmidt, J. Catal. 71 (1981) 411-422.

[31] F. Tao, M.E. Grass, Y. Zhang, D.R. Butcher, F. Aksoy, S. Aloni, V. Altoe, S. Alayoglu, J.R. Renzas, C.-K. Tsung, Z. Zhu, Z. Liu, M. Salmeron, G.A. Somorjai, JACS, 132 (2010) $8697-8703$

[32] P.A.J. Bagot, A. Cerezo, G.D.W. Smith, Surf.Sci. 601 (2007) 2245-2255.

[33] M. Salmeron, L. Brewer, G.A. Somorjai, Surf. Sci., 112 (1981) 207-228.

[34] Y. Matsumoto, Y. Okawa, T. Fujita, K. Tanaka, Surf. Sci. 355 (1996) 109-114.

[35] K. Tanaka, Surf. Sci. 357-358 (1996) 721-728.

[36] Y. Matsumoto, Y. Aibara, K. Mukai, K. Moriwaki, Y. Okawa, B.E. Nieuwenhuys, K. Tanaka, Surf. Sci. 377-379 (1197) 32-37.

[37] I. Rodriguez-Ramos and A. Guerrero-Ruiz, J. Catal., 135 (1992) 458-466.

[38] L.I. Ali, A.-G.A. Ali, S.M. Aboul-Fotouh, A.K. Aboul-Gheit, Appl. Catal. A 177 (1999) 99-110.

[39] W.M.H. Sachtler, R.A. Van Santen, Appl.Surf.Sci., 3 (1979) 121.

[40] F.G. Gault, Adv. Catal. 30 (1981) 1-95.

[41] M. Daage, G.B. McVicker, M.S. Touvelle, C.W. Hudson, D.P. Klein, W.C. Baird, B.R. Cook, J.G. Chen, S. Hantzer, D.E.W. Vaughan, E.S. Ellis, Stud. Surf. Sci. Catal. 159 (2001) 135.

[42] Z.-J. Zhao, L. V. Moskaleva, N. Rösch, ACS Catalysis, 3 (2013) 196-205.

[43] G. Maire, G. Plouidy, J.C. Prudhomme, F.G. Gault, J. Catal. 4 (1965) 556-569. 
[44] D. Teschner, Z. Paál, D. Duprez, Catal. Today 65 (2001) 185.

[45] B. Coq, R. Dutartre, F. Figueras, T. Tazi, J. Catal. 122 (1990) 438. 
Table 1: Properties of monometallic and bimetallic catalysts: metallic content, particles size and metallic accessibility.

\begin{tabular}{|c|c|c|c|c|c|}
\hline \multirow[t]{2}{*}{ Catalyst } & \multicolumn{2}{|c|}{ Metal content (wt.\%) } & \multirow[t]{2}{*}{$\mathbf{H} / \mathbf{M}$} & \multirow[t]{2}{*}{$<\mathrm{d}>^{\mathrm{a}}(\mathbf{n m})$} & \multirow[t]{2}{*}{$\langle\mathrm{d}\rangle^{\mathrm{b}}(\mathrm{nm})$} \\
\hline & $\mathrm{Pt}$ & $\mathrm{Rh}$ & & & \\
\hline $\mathbf{P t}$ & 1.1 & 0 & 0.72 & 1.3 & \\
\hline $\mathbf{R h}$ & 0 & 0.6 & 0.64 & 1.4 & - \\
\hline$(\mathrm{PtRh}) / \mathrm{CI}$ & 0.9 & 0.4 & 0.71 & 1.3 & 1.3 \\
\hline Pt-Rh/OG & 1.0 & 0.6 & 0.29 & 3.1 & 3.0 \\
\hline (PtRh)/MS & 1.2 & 0.6 & 0.27 & 3.4 & 2.6 \\
\hline
\end{tabular}

${ }^{\text {a }}$ Calculated from $\mathrm{H}_{2}$ chemisorption results (with $\mathrm{H} / \mathrm{M}=1$ )

${ }^{\mathrm{b}}$ Calculated from TEM pictures 
Table 2: Pt-CO and Rh-CO species and their associated wavenumber in IR spectroscopy $[3,16,17$, $18,19,22]$

\begin{tabular}{|c|c|}
\hline M-CO species & Associated wavenumber $\left(\mathrm{cm}^{-1}\right)$ \\
\hline $\mathbf{P t}^{0}-\mathrm{CO}$ (faces) & $2095-2077$ \\
\hline $\mathbf{P t}^{0}-\mathrm{CO}$ (edges) & $2083-2068$ \\
\hline $\mathrm{Pt}^{0}-\mathrm{CO}$ (corners) & 2066-2041 \\
\hline $\mathrm{Pt}^{0}-\mathrm{CO}$ (isolated corners) & $2054-2000$ \\
\hline $\mathbf{P t}^{0}{ }^{-}-\mathbf{C O}^{(a)}$ & $1885-1840$ \\
\hline $\mathbf{R h}^{\mathbf{0}}-\mathbf{C O}$ & $2070-2040$ \\
\hline $\mathbf{R h}^{0}{ }_{x}-\mathbf{C O}^{(\mathbf{a})}$ & 1850 \\
\hline $\mathrm{Rh}^{\mathrm{I}}-(\mathrm{CO})_{2}$ antisymmetric & 2030 \\
\hline $\mathrm{Rh}^{\mathrm{I}}-(\mathrm{CO})_{2}$ symmetric & 2100 \\
\hline $\mathrm{M}^{0}-\mathrm{CO}(\mathrm{M}$ : atom of Pt-Rh alloy) & $2063-2058$ \\
\hline
\end{tabular}

(a) $\mathrm{x}$ : denotes $\mathrm{CO}$ adsorbed on bridged form $(\mathrm{x}>1)$. 
Table 3: Metallic surface composition of the $\mathrm{Al}_{2} \mathrm{O}_{3}$ supported bimetallic PtRh catalysts determined by NO-CO/FTIR, CO/FTIR.

\begin{tabular}{|c|c|c|c|c|c|}
\hline Catalyst & Method & $\begin{array}{l}\text { Pt at the } \\
\text { surface } \\
\left.(\mu \mathrm{mol} \mathrm{g})^{-1}\right)\end{array}$ & 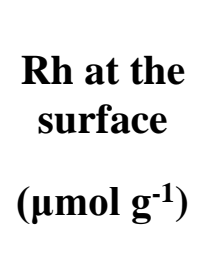 & $\begin{array}{c}\text { Rh or Pt } \\
\text { at the } \\
\text { surface } \\
\left.(\mu \mathrm{mol} \mathrm{g})^{-1}\right)^{b}\end{array}$ & $\begin{array}{c}\text { Atoms of Pt } \\
\text { in a Pt-Rh } \\
\text { alloy at the } \\
\text { surface } \\
\left.(\mu \mathrm{mol} \mathrm{g})^{-1}\right)\end{array}$ \\
\hline \multirow[t]{2}{*}{$(\mathbf{P t R h}) / \mathrm{CI}$} & NO-CO/FTIR & 12.6 & 26 & - & \\
\hline & CO/FTIR & 12.6 & n.d. ${ }^{a}$ & 26.0 & \\
\hline \multirow[t]{2}{*}{ Pt-Rh/OG } & NO-CO/FTIR & 9.5 & 14.2 & & - \\
\hline & CO/FTIR & 9.8 & n.d. ${ }^{a}$ & & 8.0 \\
\hline \multirow[t]{2}{*}{$(\mathbf{P t R h}) / \mathrm{MS}$} & NO-CO/FTIR & 5.0 & 4.4 & - & - \\
\hline & CO/FTIR & 6.5 & & 1.9 & 1.0 \\
\hline
\end{tabular}

a not determined by CO-FTIR

${ }^{\mathrm{b}}$ determined by difference between the total amount of metals at the surface and the amount of Pt or alloyed metal calculated from CO-FTIR spectra. 

Table 4: Rh-NO, Pt-NO and $\mathrm{Al}_{2} \mathrm{O}_{3}-\mathrm{NO}$ species and their associated wavenumber in IR spectroscopy

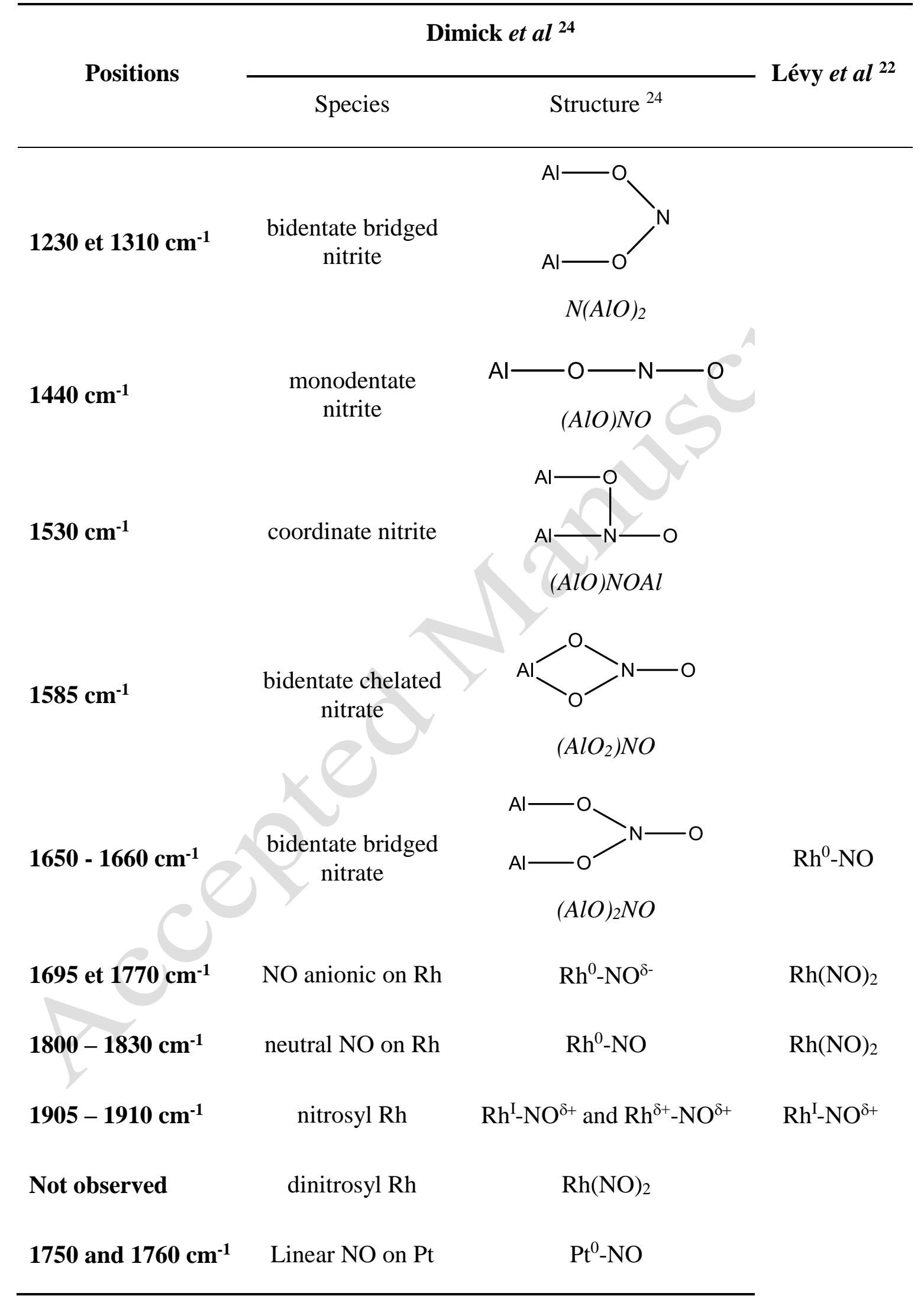




$\begin{array}{ccc}\text { 1400-1650 } \mathrm{cm}^{-1} & \text { No-linear NO on } \\ \mathrm{Pt} & \mathrm{Pt}^{0}-\mathrm{NO}\end{array}$

Table 5: Results of cyclohexane dehydrogenation $(\mathrm{CH})$ and methylcyclopentane ring-opening (MCP) obtained with mono and bimetallic catalysts and selectivity in ring-opening (RO) products and in various $\mathrm{RO}$ products (2MP, $3 \mathrm{MP}, \mathrm{nC6})$.

\begin{tabular}{|c|c|c|c|c|c|c|c|}
\hline \multirow[t]{2}{*}{ Catalyst } & \multirow{2}{*}{$\begin{array}{c}\text { Experimental } \\
\text { TOF for } \mathrm{CH} \\
\left(\mathrm{s}^{-1}\right)\end{array}$} & \multirow{2}{*}{$\begin{array}{c}\text { Calculated }^{\mathrm{a}} \mathrm{TOF} \\
\text { for } \mathrm{CH} \\
\left(\mathrm{s}^{-1}\right)\end{array}$} & \multirow{2}{*}{$\begin{array}{c}\text { TOF for } \\
\text { MCP } \\
\left(h^{-1}\right)\end{array}$} & \multicolumn{4}{|c|}{ Selectivity (\%) } \\
\hline & & & & RO & $2 \mathrm{MP}$ & $3 \mathrm{MP}$ & nC6 \\
\hline $\mathbf{P t}$ & 0.60 & - & 27 & 78 & 34 & 15 & 29 \\
\hline $\mathbf{R h}$ & 0.17 & - & 72 & 61 & 30 & 18 & 13 \\
\hline$(\mathrm{PtRh}) / \mathrm{CI}$ & 0.30 & 0.31 & 68 & 88 & 46 & 29 & 13 \\
\hline Pt-Rh/OG & 0.53 & 0.48 & 228 & 93 & 56 & 28 & 9 \\
\hline (PtRh)/MS & 0.33 & 0.51 & 179 & 93 & 63 & 27 & 3 \\
\hline
\end{tabular}


a)

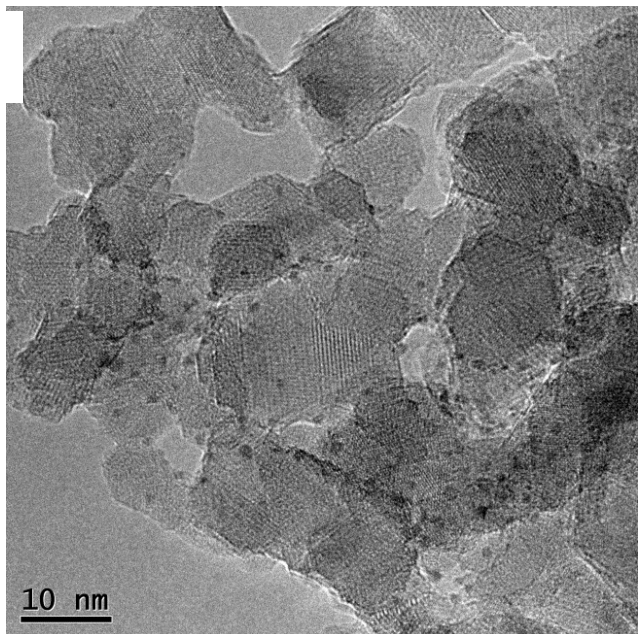

b)

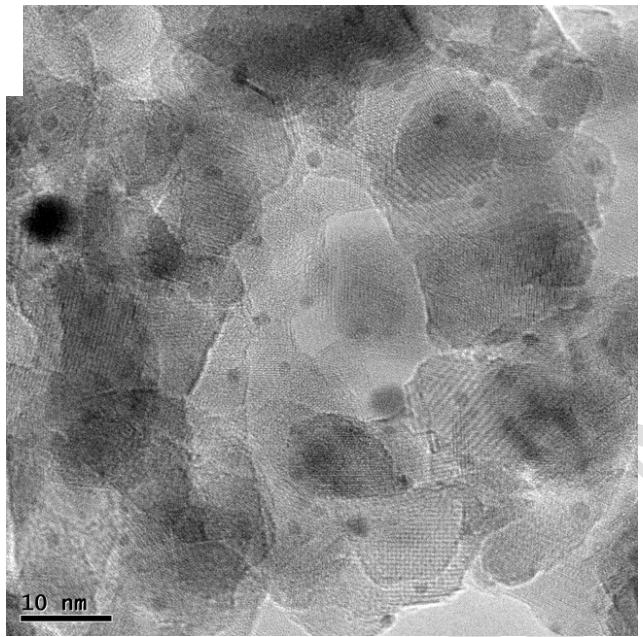

c)

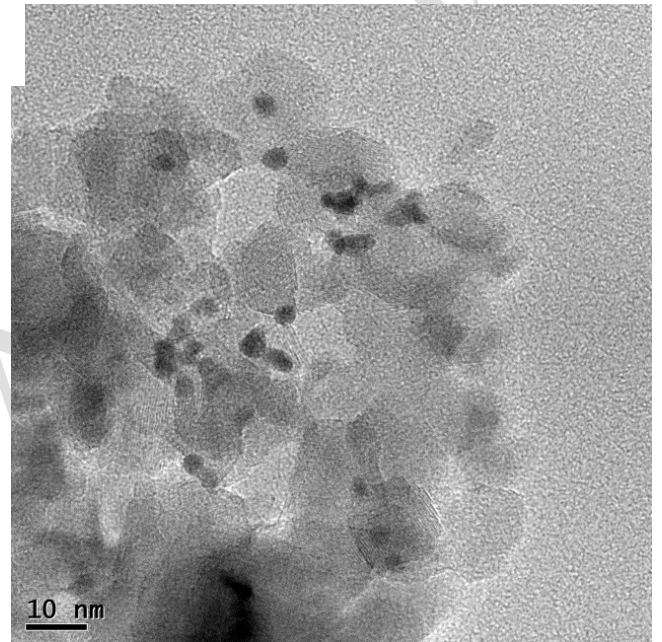

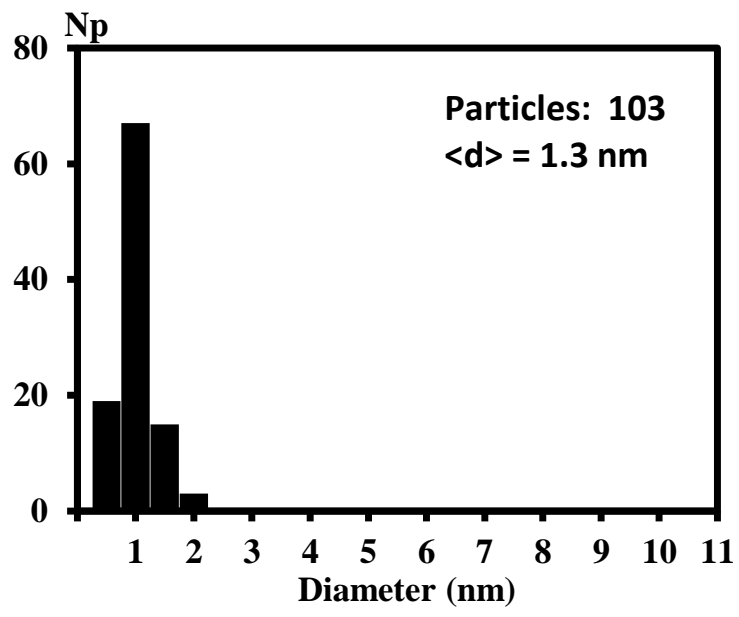
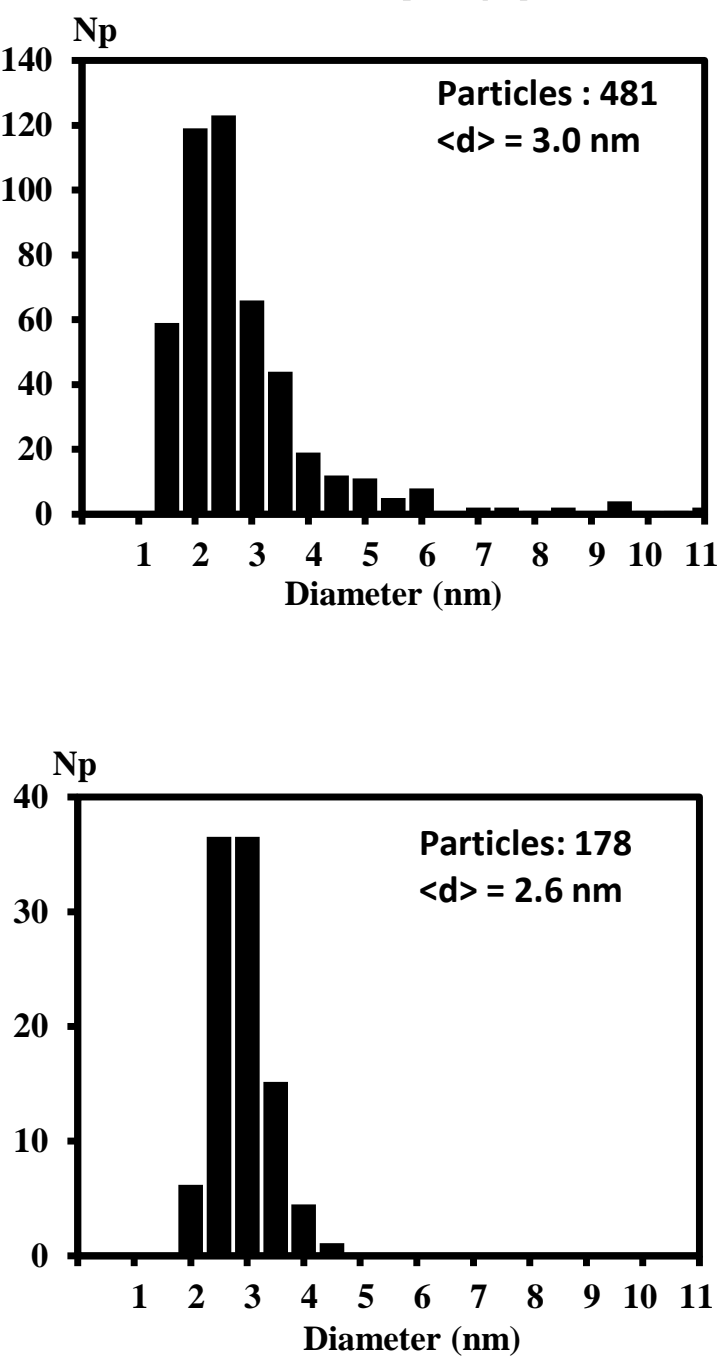

Fig. 1: TEM pictures and size distribution of the $\mathrm{Al}_{2} \mathrm{O}_{3}$ supported bimetallic PtRh catalysts a) (PtRh)/CI b) $\mathrm{Pt}-\mathrm{Rh} / \mathrm{OG}$ and c) (PtRh)/MS 


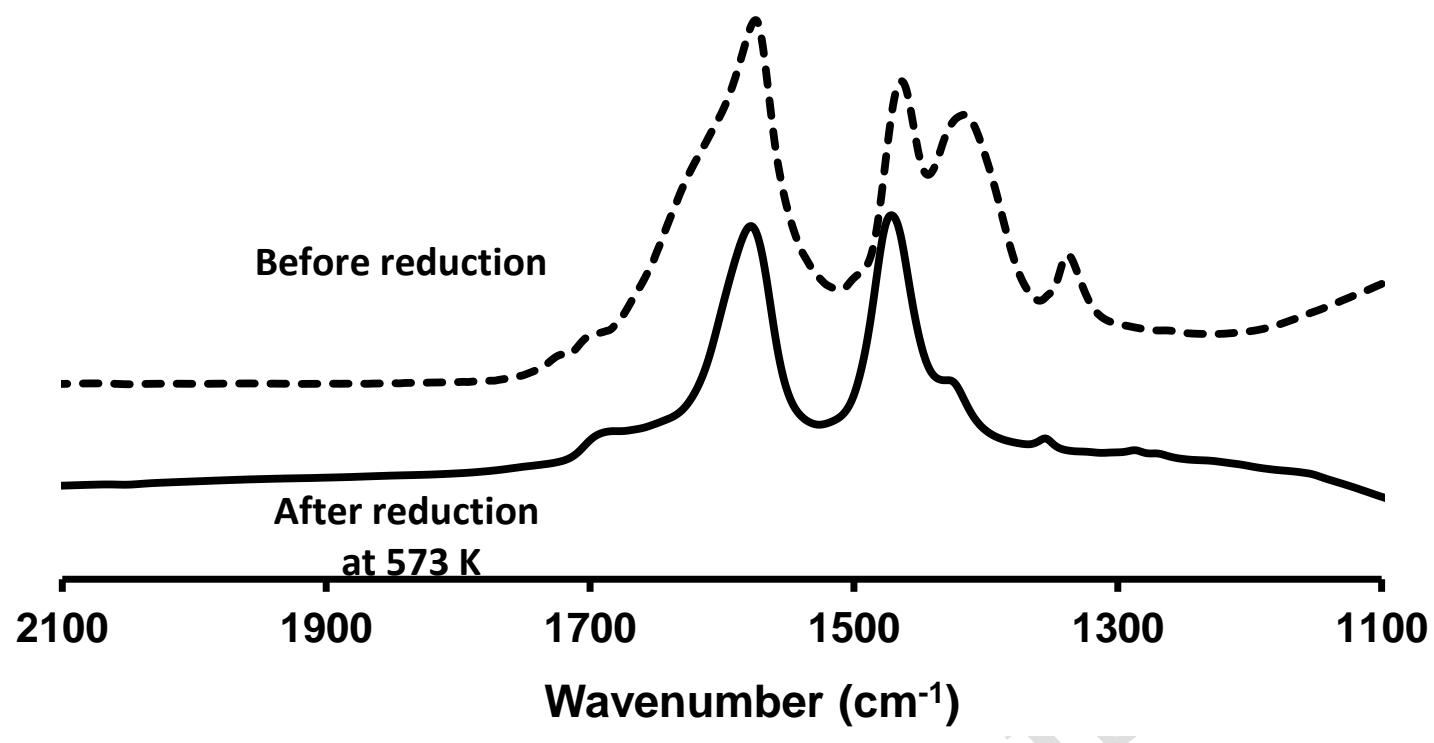

Fig. 2: Infrared spectra of the (PtRh)/MS catalyst after subtraction of the spectra of the support 


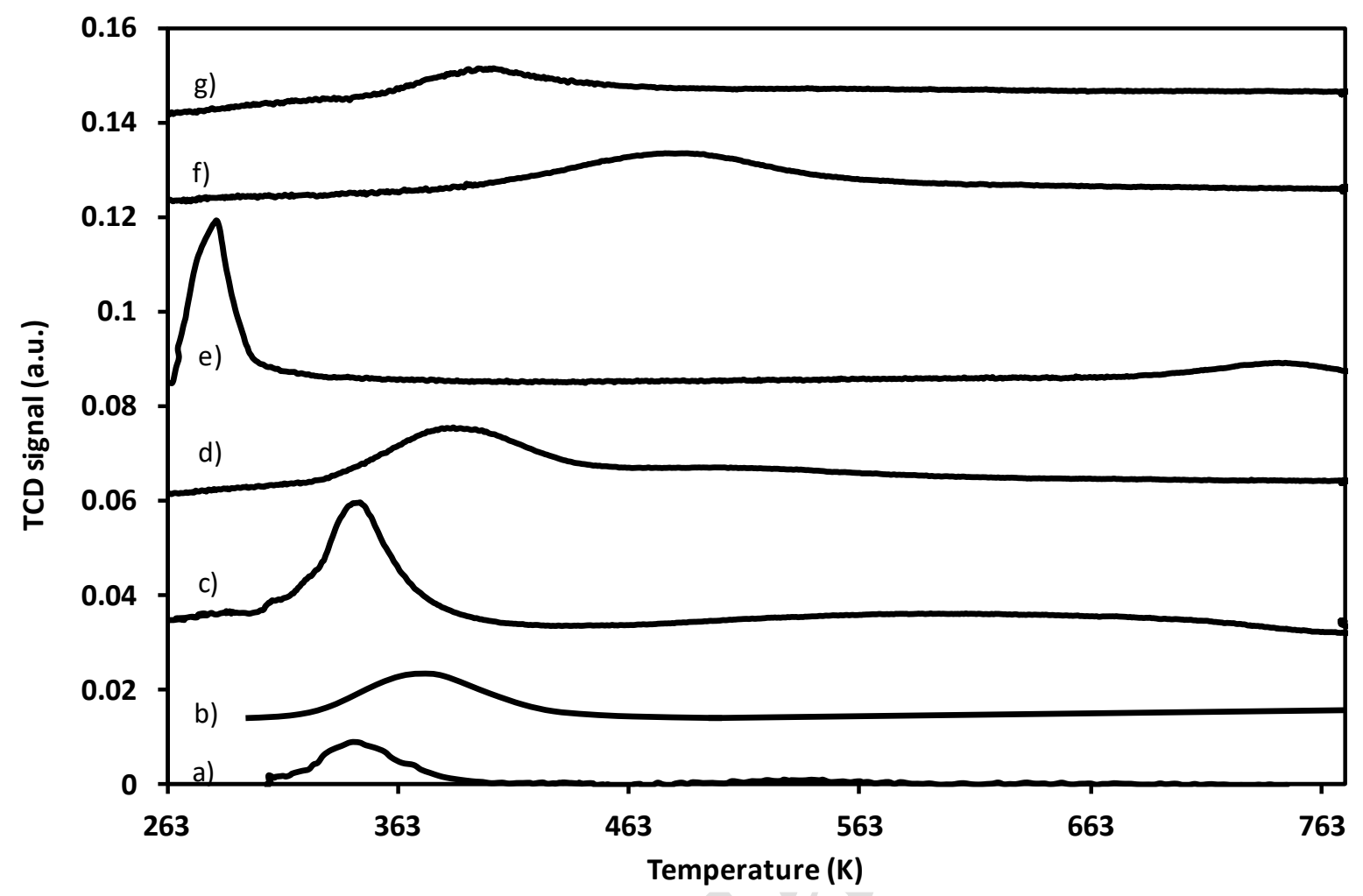

Fig.3: TPR profiles of the $\mathrm{Al}_{2} \mathrm{O}_{3}$ supported monometallic $\mathrm{Pt}$ and $\mathrm{Rh}$ catalysts prepared from organic precursors a) $\mathrm{Rh}$, b) $\mathrm{Pt}$; bimetallic PtRh catalysts c) $\mathrm{Pt}-\mathrm{Rh} / \mathrm{OG}, \mathrm{d})(\mathrm{PtRh}) / \mathrm{CI}$, e) (PtRh)/MS; monometallic $\mathrm{Pt}$ and Rh catalysts prepared from chlorinated salts f) Pt and g) Rh.

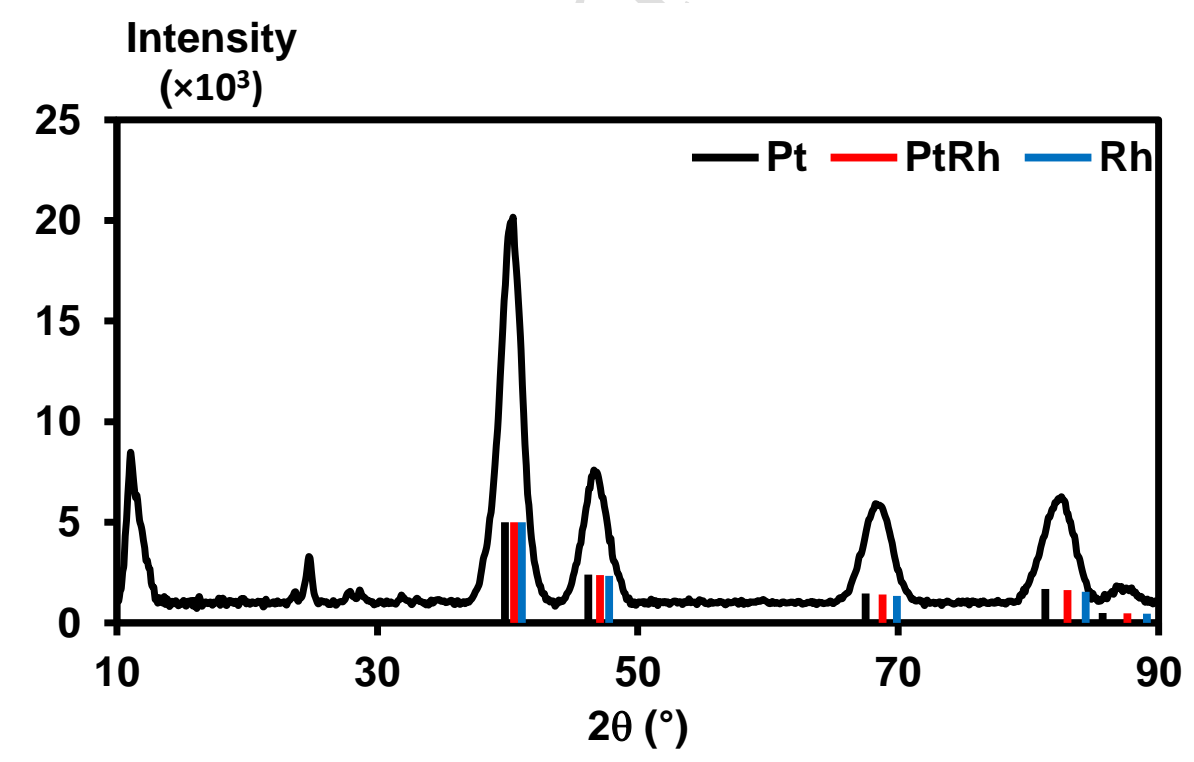

Fig. 4 : XRD patterns of metallic particles before deposition on the $\mathrm{Al}_{2} \mathrm{O}_{3}$ support during the preparation of $\mathrm{Pt}-\mathrm{Rh}$ bimetallic particles in microsuspension. 

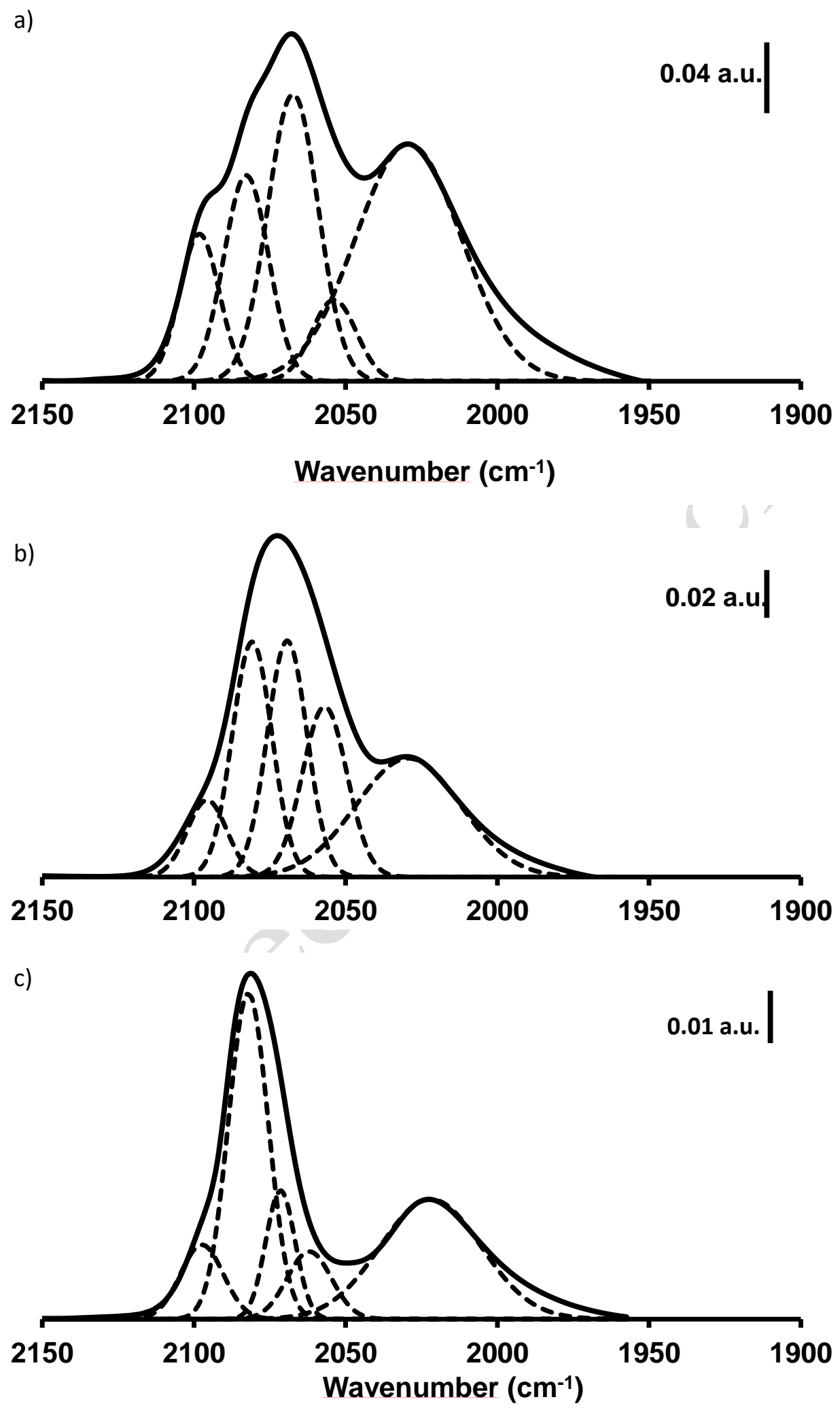

Fig. 5: Infrared spectra of the $\mathrm{Al}_{2} \mathrm{O}_{3}$ supported bimetallic $\mathrm{PtRh}$ catalysts after $\mathrm{CO}$ adsorption and their decomposition a) (PtRh)/CI, b) Pt-Rh/OG, c) (PtRh)/MS. 


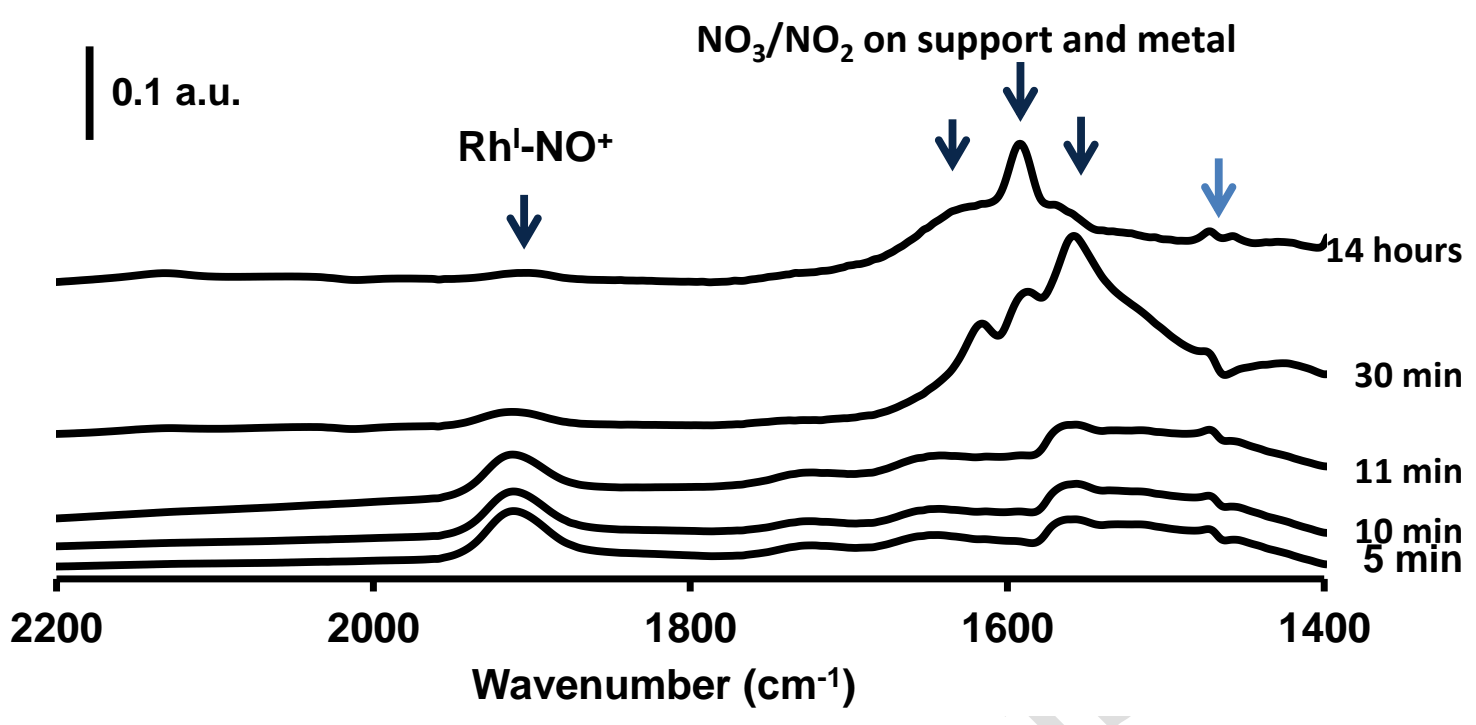

Fig. 6: Kinetic study of NO adsorption on Rh catalyst at $473 \mathrm{~K}$ 


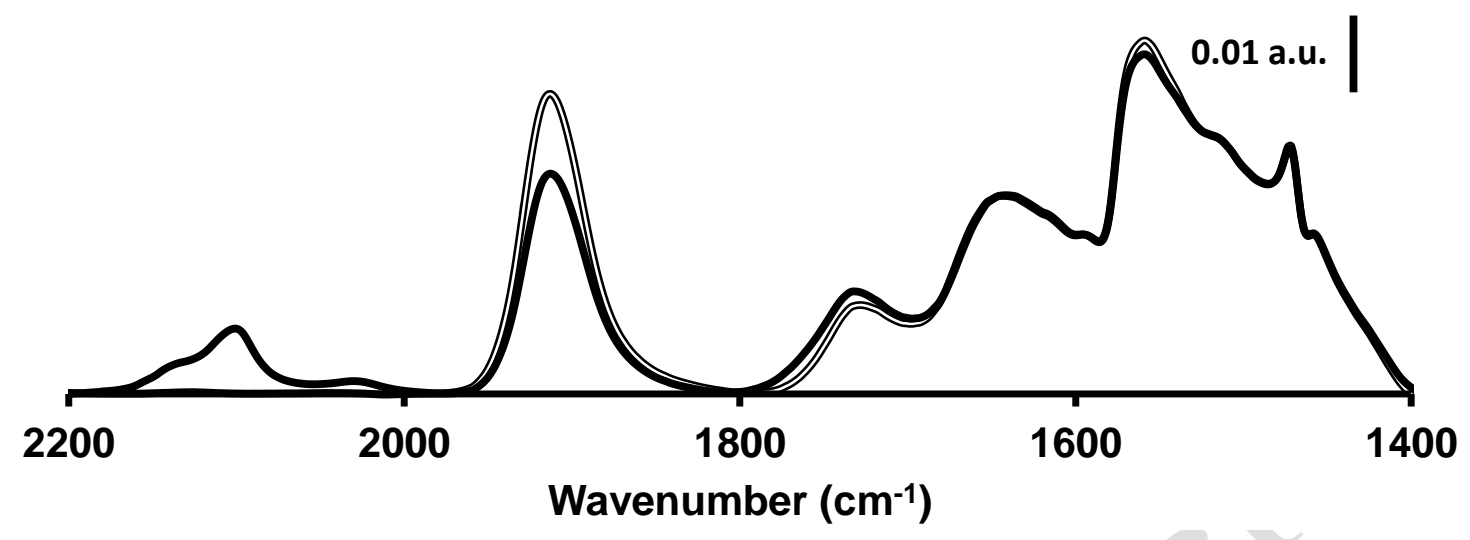

Fig. 7: Infrared spectra of $\mathrm{Rh} / \mathrm{Al}_{2} \mathrm{O}_{3}(=)$ after $\mathrm{NO}$ adsorption at $473 \mathrm{~K}$ and (-) after $\mathrm{NO}$ and $\mathrm{CO}$ adsorption 


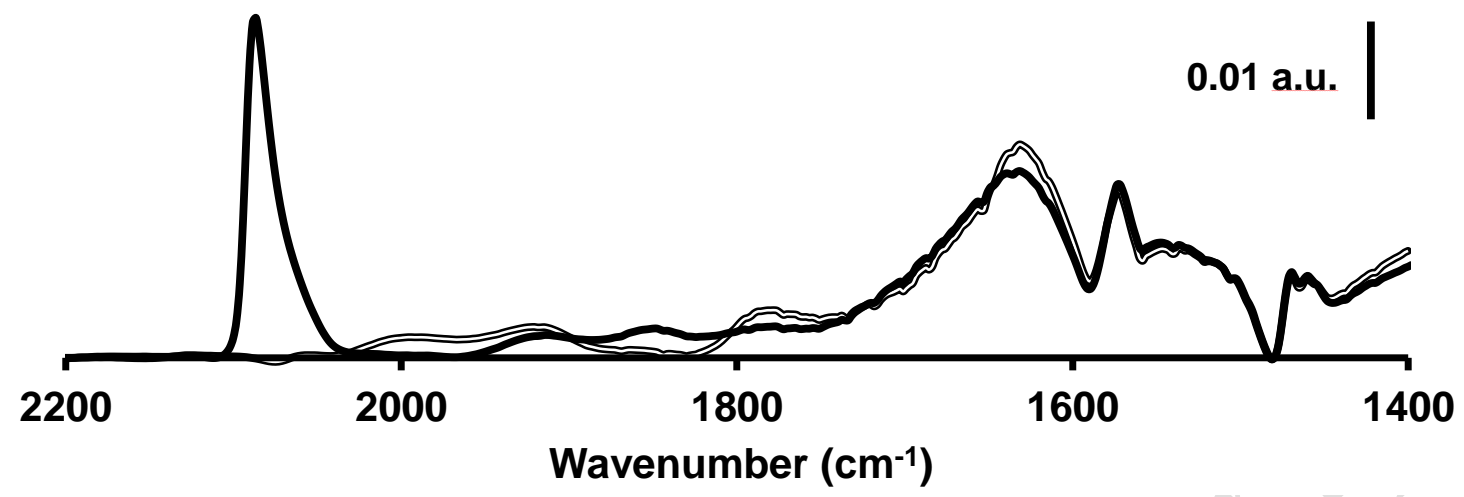

Fig. 8: Infrared spectra of $\mathrm{Pt} / \mathrm{Al}_{2} \mathrm{O}_{3}(=)$ after $\mathrm{NO}$ adsorption at $473 \mathrm{~K}$ and (-)after $\mathrm{NO}$ and $\mathrm{CO}$ adsorption 

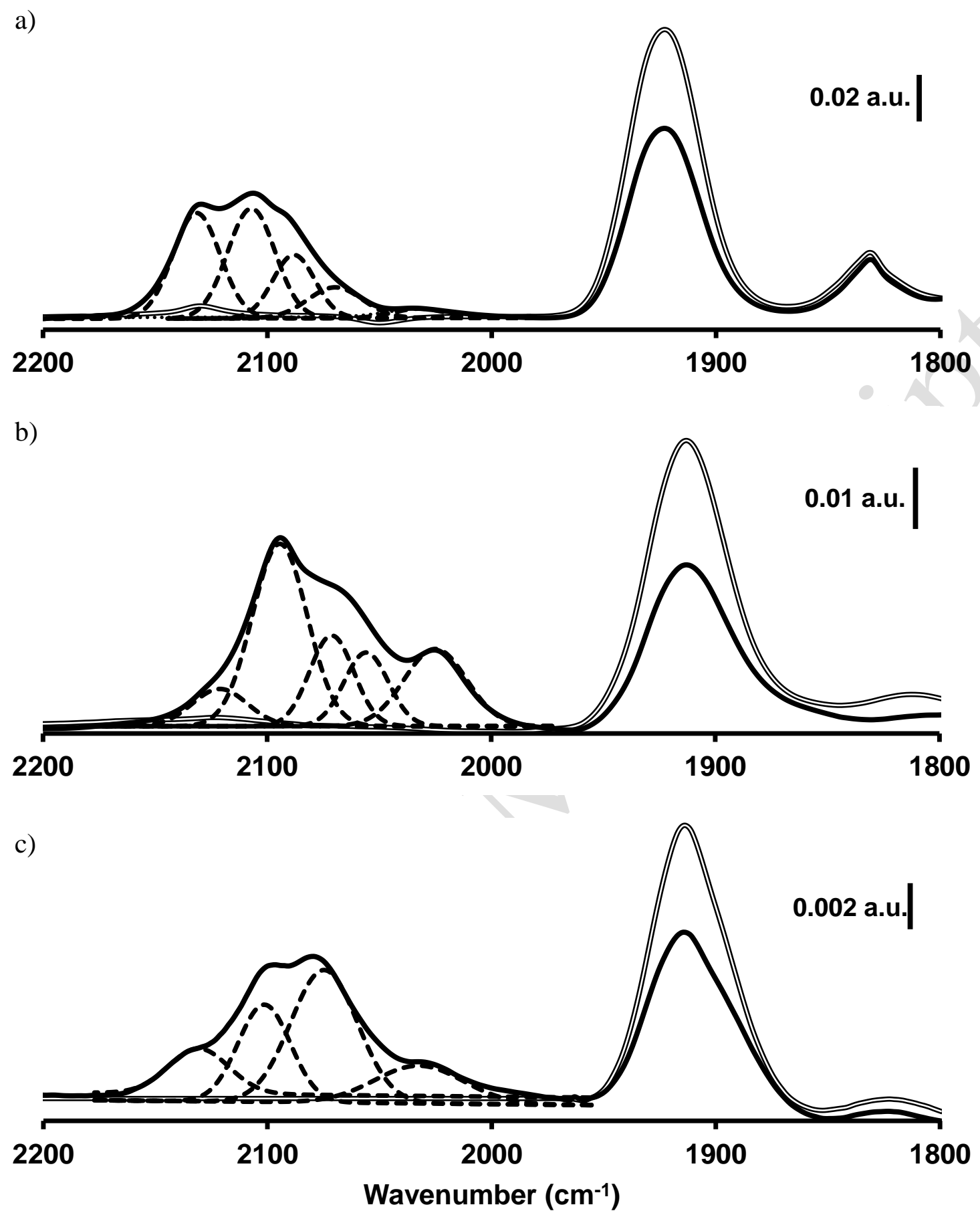

Fig. 9: Infrared spectra of the $\mathrm{Al}_{2} \mathrm{O}_{3}$ supported bimetallic PtRh catalysts (=) after NO adsorption at $473 \mathrm{~K}$ and ( - ) after $\mathrm{NO}$ and $\mathrm{CO}$ adsorption a) (PtRh)/CI, b) Pt-Rh/OG, c) $(\mathrm{PtRh}) / \mathrm{MS}$ 